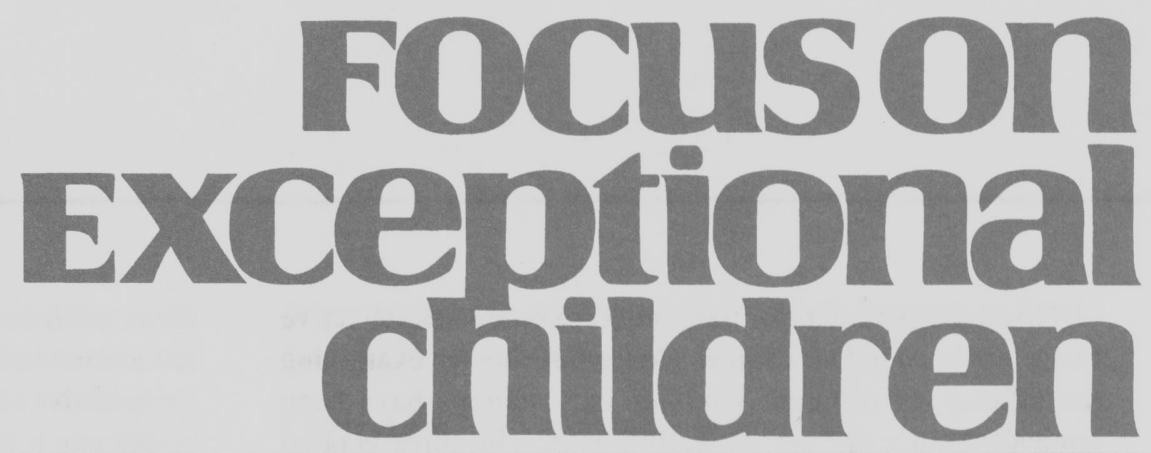

\title{
Use and Management of Medications for Children Diagnosed with Attention Deficit Hyperactivity Disorder (ADHD)
}

\author{
Scott H. Kollins, Russell A. Barkley, and George J. DuPaul
}

Attention deficit hyperactivity disorder (ADHD) is one of the most commonly diagnosed behavioral disorders among children in the United States, affecting approximately $3 \%-5 \%$ of all school-aged children (American Psychiatric Association, 1994; Barkley, 1998). ADHD is characterized by developmentally inappropriate levels of inattention, hyperactivity, and impulsivity (APA, 1994). Although the ways of characterizing the disorder have changed somewhat throughout the years, the current classification system recognizes three empirically derived subtypes of ADHD: predominantly inattentive type, predominantly hyperactive-impulsive type, and combined type (Lahey et al., 1994).

Given the demonstrated academic and social outcomes associated with ADHD, the occurrence of this disorder in school-aged children represents a significant public health concern. For example, studies of co-occurring problems suggest that children diagnosed with ADHD also are more likely to be diagnosed with oppositional defiant disorder (ODD), conduct disorder (CD), depression and other mood problems, anxiety problems, and tics (see Barkley, 1998; and Biederman, Wilens, \& Spencer, 1999, for reviews of the impairment associated with ADHD).

When studied across time, children diagnosed with ADHD are at higher risk for continuing to have learning, behavioral, and emotional problems throughout childhood and adolescence (e.g., Barkley, Fischer, Edelbrock, \& Smallish, 1991). Compared to controls, adults who were diagnosed with ADHD as children receive fewer years of formal schooling, achieve lower overall occupational status, and are more likely to have a range of psychiatric problems as adults, such as antisocial personality disorder and non-alcohol substance abuse (e.g., Mannuzza, Klein, Bessler, Malloy, \& LaPadula, 1998). Further, children with ADHD have been shown to have difficulty with social interactions with peers (e.g., Flicek, 1992) and family members (e.g., Barkley et al., 1991; Fletcher, Fischer, Barkley, \& Smallish, 1996), especially when co-occurring conditions such as learning problems or ODD are present.

Dr. Kollins is an Assistant Clinical Professor in the Department of Psychiatry, Duke University Medical Center. Dr. Barkley is with the Departments of Psychiatry and Neurology, University of Massachusetts Medical School. Dr. DuPaul is with the Department of Education and Human Services, Lehigh University. 
Given the potential for these adverse outcomes, effective treatment of ADHD is critical. Controlled studies examining the efficacy of different kinds of interventions have been conducted since at least the early 1960s, with three general approaches to treating ADHD receiving the most attention:

1. Pharmacological approaches

2. Behavioral/psychosocial approaches

3. A combination of behavioral and psychosocial approaches.

The vast majority of the scientific evidence suggests that effective treatment for children with ADHD consists of lowto-moderate doses of stimulant medication, such as methylphenidate (Ritalin) or $d$-amphetamine (Dexedrine) (see Swanson et al., 1993, for a review).

More recently, results of the largest trial ever conducted with children having ADHD became available through the Multimodal Treatment of ADHD (MTA) study sponsored by the National Institute of Mental Health. This project demonstrated that, compared to standard community-based care and a structured behavioral intervention, a carefully managed protocol of stimulant medication or a combination of

\section{Focuson
Exceptional
children}

ISSN 0015-511X

FOCUS ON EXCEPTIONAL CHILDREN (USPS 203-360) is published monthly except June, July, and August as a service to teachers, special educators, curriculum specialists, administrators, and those concerned with the special education of exceptional children. This publication is annotated and indexed by the ERIC Clearinghouse on Handicapped and Gifted children for publication in the monthly Current Index to Journals in Education (CIJE) and the quarterly index, Exceptional Children Education Resources (ECER). The full text of Focus on Exceptional Children is also available in the electronic versions of the Education Index. It is also available in microfilm from Xerox University Microfilms, Ann Arbor, MI. Subscription rates: Individual, \$30 per year; institutions, \$40 per year. Copyright (C) 2001, Love Publishing Company. All rights reserved. Reproduction in whole or part without written permission is prohibited. Printed in the United States of America. Periodicals postage is paid at Denver, Colorado. POSTMASTER: Send address changes to:

$$
\begin{gathered}
\text { Love Publishing Company } \\
\text { Executive and Editorial Office } \\
\text { P.O. Box } 22353 \\
\text { Denver, Colorado } 80222 \\
\text { Telephone (303) 221-7333 }
\end{gathered}
$$

Karen Harris

University of Maryland

James Shriner

University of Illinois
Thomas Skrtic University of Kansas
Stanley F. Love Publisher medication and behavioral intervention led to the greatest reductions in ADHD symptoms across participants (MTA Cooperative Group, 1999).

Although this study reported that the combination of medication plus behavioral intervention did not reduce ADHD symptoms more than the medication protocol alone, the combined treatment was associated with lower effective doses of medication. Moreover, compared to the medication management intervention, both the combined and the behavioral intervention received significantly higher parent satisfaction scores at the end of the 14-month trial. The behavioral intervention was also equal in efficacy, though not superior to medication management for some aspects of problem behavior often observed in children with ADHD, such as oppositional/aggressive behavior, social skills, parent-child relations, and academic achievement (MTA Cooperative Group, 1999).

Although the MTA collaborative study is the largest and longest trial of medication with children with ADHD, its duration (14 months) is still relatively short in comparison to the duration of time that many children are prescribed the medications. As such, information regarding the long-term risks and benefits of using medications with children is limited.

The widespread use of stimulant medication in treating childhood behavior problems has been accompanied by substantial controversy, much of which has been generated in the popular media and outside of the scientific literature. In particular, the long-term safety and efficacy of the use of chronic medication has been called into question. For example, chronic use may increase the risk for substance use and abuse later in life. Although at least one study found the opposite to be true (Biederman, Wilens, Mick, Spencer, \& Faraone, 1999), the issue of whether the use of stimulants has significant long-term effects, either positive or negative, is yet to be resolved conclusively.

Another controversial issue pertaining to the use of stimulant drugs (and other classes of drugs) is the growing frequency with which these are prescribed for behavioral problems in children and adolescents. One study documented the increased use of psychotropic medications in children, especially those younger than 6 years of age (Zito et al., 2000). This study reported 1.7-3.1-fold increases in the use of medication (most often Ritalin) for the treatment of behavior problems in preschool children. The causes for these increases have yet to be identified conclusively.

A rise in use of medication alone is not necessarily cause for alarm or prima facie evidence of overdiagnosis or overmedication. An estimated $6 \%-9 \%$ of preschool children have serious mental disorders, and a large percentage of those disorders have been shown to be responsive to medication in school-age children (e.g., Lavigne et al., 1996). 
These findings, coupled with the fact that children with these disorders have been grossly underdiagnosed and undertreated in previous decades, support a reasonable case for increasing the use of medication with this age group (e.g., Jensen et al., 1999). These controversial issues surrounding the use of Ritalin and other drugs in children have led federal policy-makers to make research in this area a high priority (e.g., Otto, 2000).

These studies highlight several important facts regarding $\mathrm{ADHD}$ and its treatment.

- ADHD is a significant problem affecting millions of children and is associated with a number of potentially adverse outcomes.

- Converging evidence suggests that a well monitored pharmacological intervention is a critical component for managing the symptoms of ADHD.

- Psychosocial treatments often should be included in the management of comorbid psychiatric and educational disorders frequently co-existing with ADHD.

- A number of important issues remain unresolved concerning the use of medications in treating childhood behavior problems.

The purpose of this article is to help provide information and guidelines for the effective use of medications in treating ADHD. Our goals are threefold.

1. We describe some basic principles of psychopharmacology and provide information on the medications that have been used to treat ADHD successfully.

2. We explain current "best practices" for assessing the effects of medication for treatment of ADHD.

3. We discuss some of the limitations of our knowledge regarding the effects of medication in children, including areas still under study.

\section{BASIC PRINCIPLES OF PSYCHOPHARMACOLOGY}

Psychopharmacology is the study of the psychological and behavioral effects of drugs. Teachers and parents who are knowledgeable about basic principles of psychopharmacology will be able to better understand the manner in which medications alleviate behavior problems in the children with whom they interact. We will describe four basic concepts:

1. Clinical effects versus the side effects of medication.

2. The "dose-response" relation.

3. Half-life.

4. Peak effects.

We then describe the three major classes of medications that have been studied for treating ADHD, as well as specific drugs from these classes and the research findings and risks associated with the use of each drug.

\section{Clinical Effects Versus Side Effects}

When medication is used to treat ADHD, or any other behavioral or emotional problem, the goal is to achieve a "clinical" effect. That is, the drug should reduce impairment, typically by reducing the behavior/emotional problems that are causing difficulty in a person's life, and thereby provide some relief from suffering. If possible, the medication also should promote the individual's adaptive effectiveness-school functioning, peer acceptance, family functioning, and so on.

These drugs sometimes are referred to as "psychoactive" or "centrally acting drugs." This is because the primary site of action for these drugs lies somewhere in the central nervous system (CNS): the brain, the spinal cord, and the peripheral nerves. Drugs that act in the CNS have the potential to influence the functioning of all aspects of mood, behavior, and the whole range of psychological processes, including attention, concentration, sensation, perception, mood, motivation, appetite, and motor behavior.

Furthermore, centrally acting drugs usually exert their effects in the nervous system by altering the ways in which certain chemicals, known as neurotransmitters, function. Each kind of neurotransmitter usually is associated with several different kinds of functioning within the brain. For example, one common neurotransmitter known as dopamine is associated with motor activity, the ability to inhibit behavior, and motivation and reward.

Because centrally acting drugs act on neurotransmitter systems and these systems may be responsible for more than one kind of functioning, their use can result in some effects that are not of clinical interest and may even be unpleasant or unwanted. For instance, the stimulant drugs used for treating ADHD may be effective because they alter the functioning of the neurotransmitters norepinephrine and dopamine, which are associated with processes such as attention and concentration. The clinical effects of stimulant drugs, then, are the result of action in specific neurotransmitter systems (for a review of how drugs work on neurotransmitter systems, see Wilens, 1999). These neurotransmitters, however, also are associated with elevated arousal elsewhere in the central nervous system. Consequently, in addition to the clinical effects of improving concentration and attention, these drugs may increase blood pressure and heart rate, increase respiration, decrease appetite, and disrupt sleep patterns in some individuals.

Part of the successful management of any behavioral or psychological problem through the use of medication is to balance the beneficial clinical effects of the medication with the potential side effects. The approach for striking a balance 
is discussed below in addressing best practices for assessment of medication effects. To summarize, though, because of the way that drugs work in the nervous system, many drugs that positively change some aspect of behavior, thinking, or emotion might also have other, not-so-positive side effects.

\section{The "Dose-Response" Relation}

A basic principle of pharmacology is that the effects of a drug (a "response" of some sort related to behavior change) are systematically related to the amount of drug (the "dose") in the body. This relation, called the dose-response function, can be displayed graphically to show the effects of various doses of a drug on some aspect of behavior. One important facet of the dose-response function is that the manner in which doses influence various areas of functioning (academic, social, emotional) varies considerably, both across children and even within the same child (Douglas, Barr, Desilets, \& Sherman, 1995; Sprague \& Sleator, 1977; Tannock, Schachar, Carr, \& Logan, 1989). This basic principle of psychopharmacology again underscores the need for individualized assessment of drug effects.

Another important feature of the dose-response relation is that it is not always a linear function. It is not true that if a small dose of a drug is moderately effective in managing some problem behavior, a larger dose always will be better. The way in which different children respond to medications could result in very different dose-response profiles. The response of individual children to varying doses of a drug can be categorized in at least four ways (e.g., Rapport, DuPaul, Stoner, \& Jones, 1986):

1. Behavioral improvement is related to step-wise increases in dose;

2. Behavioral improvement is subject to a "threshold" effect at a moderate or high dose;

3. Behavioral improvement reaches a peak at a moderate dose and shows a decrease at higher doses; or

4. Behavioral improvement is inconsistent across doses.

These patterns of responding are illustrated in Figure 1, which also shows how the dose-response relationship can be presented graphically.

This figure also highlights the necessity of examining several different doses of medication to determine conclusively which dose is optimal for managing a specific behavioral problem. For example, if a clinician were to prescribe only a relatively high dose of medication to the child in Panel C without also evaluating other doses, he or she could conclude erroneously that the medication was not effective because this specific dose had little effect. Similarly, prescribing only a low dose for this child would not have much effect. Only by examining different doses in comparison to one another can a physician determine confidently which dose is the most effective for managing a behavior problem.

\section{Half-Life}

Another related pharmacological principle is that drugs are broken down and eliminated from the body over a specific time course and, as this happens, less drug is available in the system to influence behavior across the time period. Because, as we just described, the effects of a drug are related to the amount of drug in the body, it follows that the faster the drug is broken down and eliminated from the body, the shorter is the amount of time the drug will exert its effects. This is exactly the case.

The rate at which different drugs are broken down and eliminated from the body is described generally as the halflife of a medication. This term is used to describe the time required to eliminate half of a drug from the body (hence the term half-life). For example, the half-life of normally administered methylphenidate (Ritalin) is 2 to 3 hours (Julien, 1998). This means that it takes between 2 and 3 hours for half an initial dose to be eliminated from the body. This also means that 4 to 6 hours after taking a dose of methylphenidate, only $25 \%$ is left in the body- $50 \%$, or half of the drug, is left after the first $2-3$ hours, and $50 \%$ of $50 \%$ $(25 \%)$ is left after another 2-3 hours.

The half-life of other drugs can be much longer. For example, fluoxetine (Prozac), an antidepressant drug that has been used to treat ADHD has a half-life of 1 to 4 days. This means that, especially if the medication is administered daily, it takes much longer for the drug to be eliminated completely from the body. Conversely, it also means that it may take several days (or weeks) for a drug to reach "therapeutic levels" in the body.

For example, suppose that a drug has a half-life of 1 day (24 hours) and a dose of $10-\mathrm{mg}$ is prescribed once daily. On the second day, $5 \mathrm{mg}$ is left in the body, and this is added to that day's additional $10 \mathrm{mg}$ dose. On the third day, $2.5 \mathrm{mg}$ of the original dose, plus $5 \mathrm{mg}$ of the second dose, plus 10 $\mathrm{mg}$ of that day's dose is left in the body, for a total of 17.5 $\mathrm{mg}$. This regimen may be continued until reaching a certain level of the drug in the body, at which time the dosing regimen may be altered to maintain this level.

One might ask why not just administer a larger dose all at once? In general, this might not be possible with some drugs because of potentially problematic side effects of large doses given in one administration. In any case, an understanding of the concept of half-life of drugs is important to help teachers and parents understand the dosing regimen on which their child may be placed. Further, this information might be helpful in determining whether changes or aberrations in behavior or other functioning of a child are likely the result of drug effects or other factors. 

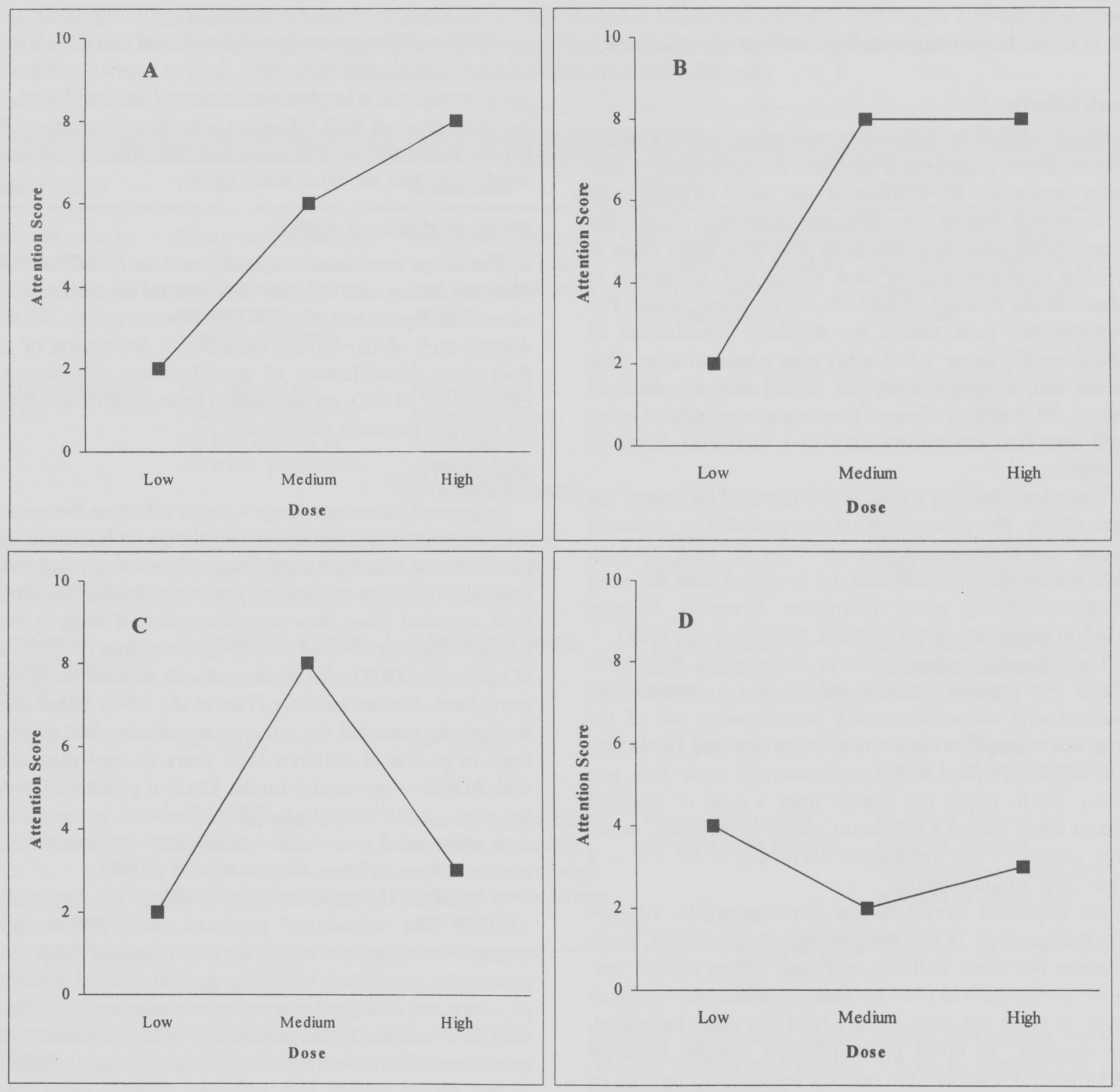

Note: Scores on a rating of attention (higher = better) are plotted as a function of drug dose.

FIGURE 1

Different Dose-Response Patterns for Several Different Doses of a Drug.

The half-life of a given medication typically varies somewhat across individuals. For example, the average half-life of methylphenidate (Ritalin) is between 2 and 3 hours. For a child in whom Ritalin has a half-life of 2 hours, only $25 \%$ of the medication would remain 4 hours after a dose. By contrast, a child in whom Ritalin has a half-life of 3 hours would not eliminate that much of the medication until 6 hours after a dose. These differences may require different dosing regimens for different children to attain maximum clinical efficacy. The former child may benefit from doses administered every 4 hours, whereas the latter child may benefit from a more delayed regimen. Of course, as noted 
previously, the best way to determine the best dosing schedule is to conduct an individualized medication assessment.

\section{Peak Effects}

The final basic principle of psychopharmacology that is important for parents and teachers to understand is that drugs (especially the stimulants; see Table 1) often exert their optimal clinical (i.e., behavior-improving) effects at a certain point after administration. This time point often is referred to as the time of peak effects and, because it is related to the concept of half-life, varies across drugs. For example, the peak effects for standard formulations of Ritalin usually occur 1.5-2 hours after administration. This means that, although beneficial effects may be observed sooner, the maximal effect of the drug is not likely to occur until later and the effects after that time may begin to diminish.

Sometimes the way a drug is administered influences the peak effects. For example, Ritalin is available in sustained release formulations that may influence the time at which peak effects are observed and the length of time the drug remains clinically active (Birmaher, Greenhill, Cooper, Fried, \& Maminski, 1989; Pelham, Sturges, et al., 1987).

Understanding when different drugs exert their peak effects can provide valuable information to parents and teachers who are administering or overseeing use of the drug. For example, a child whose attentional and concentration deficits are particularly problematic in math class, just before lunch, might not benefit from a dose of standard Ritalin administered 4 or 5 hours earlier at breakfast, as the peak effects of the medication likely will occur 1.5 to 2 hours after administration.

An important caveat to the above principles of psychopharmacology is that the patterns of side effects, doseresponse functions, half-life, and peak effects are not uniform across individuals. In fact, considerable variation exists in these concepts, even within the same individual. For example, as noted previously, the specific behavior under study influences the relation between the amount of drug and the extent of behavior change (the dose-response relation). Similarly, factors such as presence of other prescription or over-the-counter medications, recent meals, or sleep patterns might all influence the half-life or peak effects, or both, of drugs within the same child.

These characteristics of drug effects underscore two important facts that will be discussed below.

1. The only way to confidently determine the specific effects of a drug for any given child is to conduct a carefully controlled drug assessment.

2. Generally speaking, drugs affect individuals in different ways.
This principle of psychopharmacology is important, as it can influence the expectations of important individuals who interact with a medicated child, such as parents and teachers. For example, a teacher who observed one child in his or her class respond well following a treatment regimen with Ritalin might not see the same positive effects in another child prescribed the same medication.

\section{Drugs used to treat ADHD}

The drugs used most frequently to treat ADHD in children and adolescents fall into three general categories: stimulants, antidepressants, and antihypertensive agents. We will discuss each of these next, including a description of the drug class, identification of specific drugs shown to be effective for ADHD, recommended doses, contraindications for use, and common side effects.

\section{Stimulant Drugs.}

In general, stimulant drugs have an effect on the central nervous system that can be seen by things such as increased heart rate and blood pressure, increases in activity and alertness, and increases in thinking processes. By far, the stimulants are used more than any other class of drug to treat ADHD. Roughly $80 \%$ of school-aged children (5-14 years of age) with ADHD who are treated with medication receive some kind of stimulant drug (Zito et al., 1999). Other studies have documented the growing use of stimulant medications in preschool children (1-5 years of age) diagnosed with ADHD or presenting similar kinds of problems (Rappley et al., 1999; Zito et al., 2000). Probably as a result of their widespread use, stimulants also have been researched most widely in children diagnosed with ADHD.

A MEDLINE database search using the key terms "ADHD" and "stimulants" produced nearly 300 research studies. We will review briefly the four stimulant drugs most commonly prescribed including general clinical benefits, psychopharmacological properties, contraindications (situations in which use of the medication is not advisable), and side effects. This information is also summarized in Table 1.

1. Methylphenidate (Ritalin). Methylphenidate is the generic or chemical name for the drug Ritalin. It is the most commonly prescribed stimulant for ADHD and has been demonstrated to be effective for a wide range of problem behaviors. Some of the behavioral, emotional, and academic areas in which Ritalin has demonstrated beneficial effects include: academic productivity and accuracy (e.g., Elia, Welsh, Gulotta, \& Rapoport, 1993); parent and teacher behavior ratings (e.g., Barkley et al., 1991); aggression and other antisocial behavior (e.g., Bukstein \& Kolko, 1998); and social functioning and peer relations (e.g., Barkley \& Cunningham, 1979). 
TABLE 1

The Stimulants: Drugs, Clinical Effects, Contraindications, Dosing Information, Peak Effects, Half-life, and Side Effects

\begin{tabular}{|c|c|c|c|c|}
\hline Drug Feature & Methylphenidate & d-amphetamine & Pemoline & Mixed Amphetamine Salts \\
\hline Brand Name & Ritalin & Dexedrine & Cylert & Adderall \\
\hline $\begin{array}{l}\text { Areas Shown to } \\
\text { be improved }\end{array}$ & $\begin{array}{l}\text { Short-term academic } \\
\text { performance, teacher } \\
\text { and parent behavior } \\
\text { ratings, aggression, } \\
\text { social functioning }\end{array}$ & $\begin{array}{l}\text { Short-term academic } \\
\text { performance, teacher } \\
\text { and parent behavior } \\
\text { ratings }\end{array}$ & $\begin{array}{l}\text { Short-term academic } \\
\text { performance, teacher } \\
\text { behavior ratings, } \\
\text { on-task behavior }\end{array}$ & $\begin{array}{l}\text { Short-term academic } \\
\text { performance, teacher and } \\
\text { parent ratings, on-task } \\
\text { behavior }\end{array}$ \\
\hline $\begin{array}{l}\text { Contraindications } \\
\text { to Use }\end{array}$ & $\begin{array}{l}\text { Tics, Tourette's } \\
\text { disorder, glaucoma, } \\
\text { marked anxiety or } \\
\text { agitation, psychosis }\end{array}$ & $\begin{array}{l}\text { Hypertension, } \\
\text { hyperthyroidism, } \\
\text { cardiovascular } \\
\text { disease, tics, } \\
\text { Tourette's disorder }\end{array}$ & $\begin{array}{l}\text { Hepatic (liver) } \\
\text { problems, psychosis }\end{array}$ & $\begin{array}{l}\text { Hypertension, } \\
\text { hyperthyroidism, } \\
\text { cardiovascular disease }\end{array}$ \\
\hline $\begin{array}{l}\text { Recommended } \\
\text { Starting/ } \\
\text { Maximum Dose }\end{array}$ & $\begin{array}{l}5-10 \text { mg twice a day/ } \\
60 \text { mg daily }\end{array}$ & $\begin{array}{l}2.5-5 \mathrm{mg} \text { one or } \\
\text { two times daily/ } \\
40 \text { mg daily }\end{array}$ & $\begin{array}{l}37.5 \mathrm{mg} \text { once daily/ } \\
112.5 \mathrm{mg}\end{array}$ & $\begin{array}{l}2.5-5 \mathrm{mg} \text { once or twice } \\
\text { daily/60 mg daily }\end{array}$ \\
\hline $\begin{array}{l}\text { Duration of } \\
\text { Action/Peak } \\
\text { Effects }\end{array}$ & $3-4$ hours/1-2 hours & 4 hours $/ 2-3$ hours & $\begin{array}{l}\text { Up to } 6 \text { hours/ } \\
\text { dose-dependent, } \\
2-6 \text { hours }\end{array}$ & $\begin{array}{l}\text { Dose dependent, } 3.5-6.4 \\
\text { hours/dose dependent } \\
1.5-3.0 \text { hours }\end{array}$ \\
\hline Half-life & $2-3$ hours & $6-7$ hours & $2-12$ hours & $\begin{array}{l}\text { Not determined; probably } \\
\text { similar to } d \text {-amphetamine }\end{array}$ \\
\hline $\begin{array}{l}\text { Common } \\
\text { Side Effects }\end{array}$ & $\begin{array}{l}\text { Insomnia, decreased } \\
\text { appetite, } \\
\text { stomachaches, } \\
\text { headaches, dizziness }\end{array}$ & $\begin{array}{l}\text { Insomnia, decreased } \\
\text { appetite, irritability, } \\
\text { anxiousness, crying, } \\
\text { sadness/unhappiness, } \\
\text { nightmares }\end{array}$ & $\begin{array}{l}\text { None substantially } \\
\text { different from placebo }\end{array}$ & $\begin{array}{l}\text { Insomnia, decreased } \\
\text { appetite, but not } \\
\text { significantly different from } \\
\text { placebo at group level }\end{array}$ \\
\hline
\end{tabular}

According to the Physician's Desk Reference (PDR; 2000) the typical dose of Ritalin for children begins at $5 \mathrm{mg}$ twice daily (before breakfast and before lunch) and is adjusted upward to maximize efficacy. It is recommended that children not take more than $60 \mathrm{mg}$ per/day, although physicians will help determine the optimal dose for each child. The effects of Ritalin are not related to the child's weight (Rapport, DuPaul, et al., 1986). Heavier children do not necessarily require higher doses of Ritalin than lighter children to achieve he same clinical effects. The PDR also recommends that Ritalin not be prescribed to children younger than 6 years of age, although this practice seems to be widespread (e.g., Zito et al., 2000). Some controversy surrounds the clinical efficacy or extent of side effects reported in young children who are prescribed Ritalin. The
National Institutes of Health (NIH) currently is funding research to determine whether Ritalin is effective and safe for preschool children.

Ritalin exerts its peak effects 1-2 hours after administration and has a half-life of 2-3 hours (Julien, 1998). The duration of action of Ritalin, or the length of time its beneficial clinical effects can be observed, is approximately 3-4 hours at regular doses (Julien, 1998). Ritalin is available in a sustained-release formulation that produces more variable peak effects and half-life of the drug (Birmaher et al., 1989). Nevertheless, for some children, this formulation of drug may be preferable, and it has been shown to be effective in reducing problems associated with ADHD (e.g., Pelham, Sturges, et al., 1987; Pelham, Greenslade, et al., 1990). In June of 2000 the Alza Pharmaceutical Company received 
FDA approval for a different delivery device that should help reduce the number of doses children require each day and provide more sustained blood levels across the day. Known as OROS and marketed under the name Concerta, this small capsule contains a quantity of liquid Ritalin in a lower chamber. The upper chamber is empty when swallowed. As water is absorbed from the gastrointestinal tract into the upper chamber, however, it exerts a continuous pressure on the lower chamber, squeezing out an even amount of drug across the school day. It thereby provides for more even blood levels and hence more continuous treatment of ADHD symptoms over a longer time than standard Ritalin.

Caution is recommended in the use of Ritalin if the child has a history of tics or a history of Tourette's disorder (TD), if the child is excessively agitated or anxious, or if the child is psychotic. In these cases, closer monitoring of the child's drug response and lower initial starting doses might be necessary until the child's response can be determined more fully. Some children with these conditions can take stimulants without experiencing significant difficulties, whereas others may be at risk for adverse responses, such as worsening of their tics, anxiety, or thought disorder.

The side effects of Ritalin reported most commonly in children with ADHD are insomnia, decreased appetite, stomachache, headache, and dizziness. In a large sample of children with ADHD, all of these side effects were found to occur more frequently than in a placebo condition (in which children received a capsule with no medicine in it) and were reported with relatively equal frequency at low $(0.3 \mathrm{mg} / \mathrm{kg})$ and higher $(0.5 \mathrm{mg} / \mathrm{kg})$ doses (Ahmann et al., 1993).

2. Dextroamphetamine (Dexedrine). Dextroamphetamine, the generic name for the drug Dexedrine, also has been shown to be effective for a range of behavior problems associated with ADHD. Although equally effective as Ritalin for a number of behavior problems associated with ADHD, Dexdrine is not prescribed as frequently. This is likely because of the greater potency and longer duration of action of the drug relative to Ritalin, which may lead to more pronounced side effects with Dexedrine. As noted, Dexedrine has been shown to improve school performance (e.g., Elia et al., 1993) and teacher and parent ratings of behavior problems (e.g., Gillberg et al., 1997).

According to the $P D R$, the recommended starting dose for Dexedrine is $2.5-5 \mathrm{mg}$ once or twice daily before breakfast, and possibly before lunch. A physician then should titrate the dose upward to achieve maximum clinical effects. It is recommended that children not be prescribed more than $40 \mathrm{mg}$ daily. According to the guidelines in the PDR, Dexedrine can be used with younger children than Ritalin can (as young as 3 years of age). The peak effects come approximately 2-3 hours after administration, and the drug has a half-life of approximately 6-7 hours (Julien, 1998). This means that the peak effects typically are seen after the peak effects for Ritalin are seen. Like Ritalin, Dexedrine is available in a sustained-release formulation, thereby extending the time course of its clinical effects (e.g., Pelham et al., 1990).

Dexedrine is contraindicated, or at least should be used more cautiously, if the child experiences tics or has a history of Tourette's disorder, hypertension, hyperthyroidism, glaucoma, or cardiovascular abnormalities. Given the similarity between Dexedrine and Ritalin, it should not be surprising that the side effects are similar, although they usually are more pronounced with Dexedrine at the same dose. It has been shown to significantly increase insomnia and appetite suppression and, compared to Ritalin, has been shown to produce significantly higher levels of insomnia, irritability, crying, anxiousness, sadness/unhappiness, and nightmares (Efron, Jarman, \& Barker, 1997).

3. Pemoline (Cylert). Pemoline is the generic name for the drug Cylert. The drug typically is used either when children do not respond to other stimulants or when multiple daily dosing is not possible or is impractical. Cylert is administered only once daily, in the morning. It is generally not considered a "frontline" treatment for ADHD because of its potentially severe side effects. Cylert has been shown to be effective in improving academic performance, on-task behavior, and teacher ratings (e.g., Conners \& Taylor, 1980; Pelham, Swanson, Furman, \& Schwindt, 1995).

The $P D R$ and package information for Cylert recommend a starting dose of $37.5 \mathrm{mg}$ administered once daily and a maximum dose of $112.5 \mathrm{mg}$. Although there is some disagreement as to how long after initiation of drug treatment that clinical effects are observed, well controlled studies have demonstrated that these effects occur within 2 days of drug administration (e.g., Connors \& Taylor, 1980; Pelham, Greenslade, et al., 1990; Pelham, Swanson, et al., 1995). Peak effects for Cylert seem to depend on dose, with the highest doses evaluated (112.5 mg; Pelham, Swanson, et al., 1995), demonstrating peak effects 6 hours after administration, whereas lower doses reached peak effects $2-4$ hours after administration. The half-life for Cylert is 2-12 hours (Julien, 1998) and one controlled study of children with ADHD reported a half-life of 8.6 hours (Sallee, Stiller, \& Perel, 1992).

The most salient side effect of Cylert is its association with potentially fatal liver failure. Although this side effect is infrequent and reversible if detected early enough, the risks and associated monitoring necessary for safe use of the drug probably limit the frequency of its use (Julien, 1998). The manufacturer recommends that this drug be a last resort 
for managing children with ADHD, and at some point, it is likely to be discontinued from commercial production. Not surprisingly, the use of Cylert is contraindicated in children who have a history of liver problems. Other side effects reported with the use of Cylert are minimal and do not seem to differ substantially from those reported with the placebo (Pelham, Swanson, et al., 1995).

4. Mixed Amphetamine Salts (Adderall). Adderall is the trade name for a generic compound of mixed amphetamine salts (three forms of d-amphetamine and one of l-amphetamine). It has become available for use with ADHD relatively recently compared to the other stimulants. Adderall has been shown to be equally as effective as Ritalin in reducing problem behavior in a classroom setting, improving parent and teacher behavior ratings, and improving academic performance (Pelham, Aranoff, 1999; Swanson et al., 1998a).

The recommended starting dose for Adderall is $2.5 \mathrm{mg}$ once or twice daily for children between 3 and 6 years of age, and $5 \mathrm{mg}$ once or twice daily for children aged 6 and older. It is recommended that the maximum daily dose not exceed $40 \mathrm{mg}(P D R)$. As noted previously, Adderall has generally been shown to be as effective as Ritalin in reducing symptoms of ADHD (e.g., Pelham, Aronoff, et al., 1999) and has been shown to be somewhat more potent (i.e., lower doses of Adderall yield effects similar to higher doses of Ritalin). For example, Pelham, Aronoff, et al. (1999) demonstrated that twice daily dosing of $12.5 \mathrm{mg}$ Adderall resulted in greater effect sizes across dependent variables than either $10 \mathrm{mg}$ or $17.5 \mathrm{mg}$ of Ritalin administered twice daily.

Swanson et al. (1998a) reported that the duration of behavioral effects of Adderall was generally dose-dependent, with higher doses resulting in longer duration of action (e.g., $5 \mathrm{mg}=3.52$ hours; $20 \mathrm{mg}=6.40$ hours). This same study found similar results for the time of peak effects for Adderall, with lower doses resulting in shorter times to peak effects (e.g., $5 \mathrm{mg}=1.5$ hours; $20 \mathrm{mg}=3.0$ hours). In general, both the duration of action and the time to peak effects is longer for Adderall than Ritalin (Swanson et al., 1998a). The half-life of Adderall has not been determined conclusively, but, given its chemical composition, would be expected to be similar to that for Dexedrine (e.g., 6-7 hours).

Because Adderall is composed primarily of amphetamine salts, the contraindications are similar to those for Dexedrine: a history of hypertension, hyperthyroidism, or cardiovascular problems. Based on the few existing clinical studies of Adderall, its side effects are minimal. Side effects reported by more than $10 \%$ of the samples studied on any dose of Adderall include: insomnia, loss of appetite, sadness/ unhappiness, proneness to crying, and picking at the skin or fingers (Manos, Short, \& Findling, 1999; Pelham, Aronoff, et al., 1999; Swanson, Wigal, et al., 1998a). In general, however, these side effects did not occur significantly more frequently under Adderall conditions than conditions in which children received a placebo, suggesting that the side effects the drug itself produces are minimal.

\section{Antidepressant Drugs}

Keeping in mind that the majority of children $(80 \%$ or more) treated with medication for ADHD receive one of the stimulants listed above, we now will review some other drugs that have been shown to be useful in managing symptoms associated with ADHD. In their recent survey of prescription drug practices for children with ADHD, Zito et al. (1999) reported that $17.2 \%$ of all children with ADHD treated with medication received a pharmacological agent other than a stimulant. Typically, antidepressants or antihypertensive agents are used either when children do not respond to stimulant treatment or when co-occurring psychological, emotional, or behavioral problems are present. As their name implies, the antidepressants are used in the frontline treatment of depressive disorders. Because of the specific neurotransmitters on which they work in the nervous system, however, they also are helpful in treating ADHD. Several different sub-classes of antidepressants have been used to treat symptoms of ADHD. These subclasses and some of the specific drugs in each subclass are discussed below and are summarized in Table 2 .

1. Tricyclic antidepressants (desimpramine, imipramine). The subclass of tricyclic antidepressant drugs has been evaluated extensively since at least the 1960s for treatment of childhood behavior problems (Popper, 1997). The representative tricyclic antidepressants included here are generic names and also are identified by their trade names Norpramin (desipramine) and Tofranil (imipramine). In general, the tricyclics have been shown to improve clinician, parent, and teacher ratings of behavior in children who receive this medication (e.g., Biederman, Baldessarinini, Wright, Knee, \& Harmatz, 1989).

Some concern has been raised, however, as to whether the effects of these medications on cognition or attention are as substantial as the effects seen with stimulants (Popper, 1997). For example, one study demonstrated that imipramine did not produce changes in perceptual-motor performance tasks beyond those seen with a placebo, whereas Ritalin significantly improved performance (e.g., Spring, Yellin, \& Greenberg, 1976).

Recommended doses for the tricyclics in the treatment of ADHD are somewhat difficult to ascertain because these drugs have not been developed or marketed specifically for 
TABLE 2

The Antidepressant: Drugs, Clinical Effects, Contraindications, Dosing Information, Peak Effects, Half-life, and Side Effects

\begin{tabular}{|c|c|c|c|}
\hline Drug Feature & Tricyclic Antidepressants & $\begin{array}{l}\text { Selective Serotonin } \\
\text { Reuptake Inhibitors }\end{array}$ & $\begin{array}{l}\text { Other Antidepressant } \\
\text { compounds }\end{array}$ \\
\hline $\begin{array}{l}\text { Representative Drugs } \\
\text { (Generic name/ } \\
\text { Brand name) }\end{array}$ & $\begin{array}{l}\text { Imipramine/Tofranil (IMI) } \\
\text { Desipramine/Norpramin (DMI) }\end{array}$ & $\begin{array}{l}\text { Fluoxetine/Prozac (FLU) } \\
\text { Sertraline/Zoloft (SER) } \\
\text { Venlafaxine/Effexor (VEN) }\end{array}$ & Bupropion/Wellbutrin \\
\hline $\begin{array}{l}\text { Areas Shown to be } \\
\text { improved }\end{array}$ & Parent, teacher, clinician ratings & $\begin{array}{l}\text { Clinician, teacher ratings, } \\
\text { laboratory measures of } \\
\text { impulsivity, IQ }\end{array}$ & $\begin{array}{l}\text { Parent, teacher, clinician } \\
\text { behavior ratings, cognitive } \\
\text { performance, laboratory } \\
\text { measures of impulsivity }\end{array}$ \\
\hline $\begin{array}{l}\text { Contraindications } \\
\text { to Use }\end{array}$ & $\begin{array}{l}\text { Concurrent use of Monoamine } \\
\text { Oxidase Inhibitors (MAOIs) }\end{array}$ & $\begin{array}{l}\text { Concurrent use of } \\
\text { Monoamine Oxidase } \\
\text { Inhibitors (MAOls) }\end{array}$ & $\begin{array}{l}\text { Concurrent use of } \\
\text { Monoamine Oxidase } \\
\text { Inhibitors (MAOls), seizure } \\
\text { disorder, bulimia, or anorexia } \\
\text { nervosa }\end{array}$ \\
\hline $\begin{array}{l}\text { Recommended } \\
\text { Starting/Maximum } \\
\text { Dose }\end{array}$ & $\begin{array}{l}\text { IMl: } 25 \text { mg once daily/ } \\
75 \text { mg daily } \\
\text { DMI: } 25-100 \text { mg once daily/ } \\
150 \mathrm{mg}^{*}\end{array}$ & $\begin{array}{l}\text { PRO: } 27 \mathrm{mg} / \text { day }^{*} \\
\text { SER: } 25 \mathrm{mg} \\
\text { VEN: } 60 \mathrm{mg} / \text { day }^{\star}\end{array}$ & $\begin{array}{l}1-3 \mathrm{mg} / \mathrm{kg} \text { twice daily } \\
(35-100 \mathrm{mg} / \\
250-300 \mathrm{mg} \text { daily }\end{array}$ \\
\hline $\begin{array}{l}\text { Duration of Action/ } \\
\text { Peak Effects }\end{array}$ & Unknown & Unknown & $\begin{array}{l}\text { Effects noted within } 2 \text { weeks } \\
\text { for some variables }\end{array}$ \\
\hline Half-Life & $\begin{array}{l}\text { IMI: } 10-20 \text { hours } \\
\text { DMI: } 12-75 \text { hours } \\
\text { AMY: } 20-35 \text { hours }\end{array}$ & $\begin{array}{l}\text { FLU: } 24-96 \text { hours } \\
\text { SER: } 26 \text { hours } \\
\text { VEN: } 3-11 \text { hours }\end{array}$ & $8-14$ hours \\
\hline Common Side Effects & $\begin{array}{l}\text { Cardiac changes (arrhythmia, } \\
\text { blood pressure changes) } \\
\text { Blurred vision, dry mouth, } \\
\text { constipation** }\end{array}$ & $\begin{array}{l}\text { Nausea, insomnia, diarrhea** } \\
\text { Increases in hyperactivity }\end{array}$ & $\begin{array}{l}\text { Drowsiness, nausea, } \\
\text { skin problems }\end{array}$ \\
\hline
\end{tabular}

\footnotetext{
${ }^{*}$ Recommended doses from PDR for other problems. Doses not established for use with children with ADHD.

** Side effects not shown to occur significantly more frequently than placebo and not established in controlled studies with children with $\mathrm{ADHD}$
}

use with this population. As such, recommendations established for their use with depression may not be the same as the doses found in clinical trials to be effective for ADHD. For example, the $P D R$ recommends that the maximum daily dose of desipramine for adolescents not exceed $150 \mathrm{mg}$. In one controlled study of children and adolescents with ADHD, however, desipramine exerted beneficial effects at an average dose of $4.6 \mathrm{mg} / \mathrm{kg} / \mathrm{day}$, which translates to a daily dose of $161 \mathrm{mg}$ for a $35 \mathrm{~kg}$ adolescent (Biederman et al., 1989). Table 2 gives the initial and maximum doses listed in the PDR for each of these drugs. Where possible, the dose levels recommended for children or adolescents are included.

Tricyclics (and antidepressants in general) have a much longer half-life than the stimulants do. As such, they are considered to be longer acting, although beneficial effects often are not seen for several days following initiation of their use (e.g., Popper, 1997). Given the long and relatively wide-ranging half-life of these drugs, it is somewhat difficult to determine the duration of action and peak effect times 
as precisely for these medications. Table 2 gives the values derived from several clinical studies with children with ADHD

The primary contraindication to the use of the tricyclics (as well as the serotonin reuptake inhibitors and the atypical antidepressant Wellbutrin) is the concurrent use of another kind of antidepressant medication called monoamine oxidase inhibitors (MAOIs). Side effects of the tricyclic antidepressant medications can be substantial and are likely another reason why their use with children is limited. Common side effects reported in children include constipation, drowsiness, and increases in blood pressure (Rapoport, Quinn, Bradbard, Riddle, \& Brooks, 1974).

Tricyclics also can have potentially serious effects on cardiac (heart) functioning (e.g., Greenberg \& Yellin, 1975), and some have suggested that the risks of arrhythmias and other heart problems associated with some tricyclics (such as desipramine) are significant enough to warrant extreme caution. In fact, there have been several reports of sudden death in children who have taken these medications (e.g., Varley \& McClellan, 1997), although others have suggested that these reports are inconclusive with respect to their safety with children (e.g., Wilens et al., 1996). Many physicians recommend that the child receive an electrocardiogram (ECG) prior to the use of tricyclics, as well as when doses are changed. Other side effects common with this class of medication include blurred vision and dry mouth, the extent of these side effects in children treated for ADHD is unclear.

2. Selective serotonin-reuptake inhibitors (SSRIs). The SSRI class of antidepressants is named for the action they exert on the central nervous system and includes drugs such as fluoxetine (Prozac), sertraline (Zoloft), and venlafaxine ${ }^{1}$ (Effexor). In one early study of the effects of Prozac, teacher and clinician ratings were shown to be improved after 6 weeks of treatment (Barrickman, Noyes, Kuperman, Schumacher, \& Verda, 1991). Other, more recent studies, however, have been less conclusive. For example, one study demonstrated that in children with both ADHD and depression, neither Prozac nor Zoloft was effective in reducing attentional problems, although both drugs were effective in alleviating depressive symptoms (Findling, 1996).

Another study reported that less than half of a group of 16 children with ADHD showed improvement or tolerated side effects when treated with Effexor (Olvera, Pliszka, Luh, \& Tatum, 1996). This is in spite of the fact that this medication has been shown to be effective for adults with ADHD

\footnotetext{
Because it acts both to block the reuptake of serotonin and acts on the neurotransmitter noradrenaline, venlafaxine sometimes is considered an "atypical" antidepressant (Wilens, 1999). For purposes of organization, we will classify it with the other SSRIs.
}

(e.g., Adler, Resnick, Kunz, \& Devinsky, 1995), although these studies also reported high proportions of patients who did not tolerate side effects.

Overall, the SSRIs have been shown to be somewhat effective in managing ADHD in children and adolescents. The lack of well controlled studies, however, and the high rates of side effects and nonresponders, call into question the overall utility of these drugs as a primary therapy for ADHD.

As was the case with tricyclic antidepressants, identifying a specific recommended dose of SSRIs for children is difficult, as their use has not been studied widely in children with ADHD. The PDR does not explicitly recommend dose levels for use with children or adolescents for either Prozac or Effexor, although studies reporting their use with children with ADHD used doses that averaged $27 \mathrm{mg} /$ day ( 0.6 $\mathrm{mg} / \mathrm{kg} / \mathrm{day}$ ) for Prozac (Barrickman, Noyes, et al., 1991) and $60 \mathrm{mg} /$ day $(\sim 1.4 \mathrm{mg} / \mathrm{kg} /$ day) for Effexor (Olvera et al., 1996). The PDR does provide guidelines for doses of Zoloft with children and adolescents, as the drug has been used in young patients with obsessive-compulsive problems.

The recommended starting dose is $25-50 \mathrm{mg}$, and the maximum daily dose is $200 \mathrm{mg}$. One study of Zoloft use with ADHD and depression began with $25 \mathrm{mg}$ but failed to show significant improvement in attentional symptoms (Findling, 1996). The half-lives of the SSRIs are generally longer than even the tricyclic antidepressants, and they vary considerably: 24-96 hours for Prozac, 26 hours for Zoloft, and 3-11 hours for Effexor (Julien, 1998). Ascertaining how quickly this class of drugs exerts effects on ADHD is difficult because the studies that have been conducted have not reported ongoing results but rather, how patients were functioning at the beginning of treatment and after several weeks. Although these drugs usually are expected to take days or weeks to begin to show effects for depressive problems, more careful investigation is warranted before conclusions can be drawn about the time course of action with ADHD symptoms.

In the few published studies of SSRIs and ADHD, the side effects have been relatively minor. One study using Effexor reported that 3 of 16 participants in the sample discontinued the study because of increases in hyperactivity, and one other subject discontinued because of severe nausea (Olvera et al., 1996). Another study using Prozac reported that 6 of 19 subjects complained of side effects such as facial rash and feeling "spacey," but that these effects did not lead to dropping out of participation in the study (Barrickman et al., 1991).

3. Other antidepressants. One other antidepressant medication that has been used for treating ADHD warrants discussion and is pharmacologically unrelated to tricyclics and 
SSRIs. Bupropion, the generic name for the drug Wellbutrin², has been shown in several controlled trials (e.g., Barrickman et al., 1995; Conners et al., 1996) to improve parent, teacher, and clinician ratings of behavior. These studies also showed Wellbutrin to be effective in improving the performance of children with ADHD on measures of attention, vigilance, and impulsivity. Moreover, it has been shown to be effective in treating youth with ADHD who also have concurrent conduct problems such as aggression and substance use/abuse (Riggs, Leon, Mikulich, \& Pottle, 1998).

The doses used to treat children and adolescents with ADHD have ranged from 1.4-6.0 mg/kg/day (maximum daily dose $250 \mathrm{mg}$ ) (Barrickman, Perry, et al., 1995; Conners et al., 1996). The study examining ADHD adolescents with concurrent problems with drug use and conduct problems found a maximum daily dose of $300 \mathrm{mg}$ to be effective (Riggs et al., 1998). Beneficial effects of Wellbutrin have been observed as soon as 3 days after drug treatment began (Conners et al., 1996), and clinical improvements have been maintained after continued administration for up to 6 weeks (Barrickman, Perry, et al., 1995).

In addition to its contraindication with the concurrent use of MAOIs, Wellbutrin should not be used if a child or adolescent has problems with bulimia or anorexia nervosa or has a history of seizure problems, as the drug may complicate these problems. Wellbutrin has a relatively benign profile of side effects. Skin problems, drowsiness, and nausea have all been reported as adverse side effects in Wellbutrin studies with children having ADHD, although these reactions typically were not more frequent than those reported by individuals receiving capsules containing no active medication (Barrickman, Perry, et al., 1995; Conners et al., 1996).

\section{Antihypertensive Drugs}

At least two drugs that are used primarily for managing high blood pressure have been shown to be effective in some cases in the management of ADHD in children. We briefly review the profile of clinical and side effects for two of these drugs for which controlled clinical studies exist. A summary of these findings is presented in Table 3.

1. Clonidine (Catapres). Clonidine is the generic name for the drug Catapres, which is used to lower blood pressure in adults. Its use for managing ADHD in children and adolescents has increased, and one review reported 39 published studies of the use of clonidine in ADHD (Connor, Fletcher, \& Swanson, 1999). In these studies, clonidine at

\footnotetext{
${ }^{2}$ Bupropion also is marketed under the brand name Zyban as a smoking-
} cessation drug. doses between 0.1 and $0.24 \mathrm{mg} /$ day has been shown, on average, to be effective in reducing clinician, parent, and teacher ratings of problematic behavior in a manner comparable to that of the tricyclic antidepressants (Connor et al., 1999). The time course of action for clonidine in children diagnosed with ADHD remains unclear, although, according to the $P D R$, the drug has effects on blood pressure within an hour after administration and reaches its peak effects 2 to 4 hours after administration.

Side effects of clonidine that were commonly reported in the Connor et al. (1999) review included sedation and irritability. Not surprisingly, several of the studies also reported cardiac changes, including drops in blood pressure and heart rate (Connor, Barkley, \& Davis, 2000). Because of the potential for changes in cardiac functioning as a result of clonidine use, it has been recommended that children receiving the drug undergo ECG monitoring (Cantwell, Swanson, \& Connor, 1997). Only three studies reviewed by Connor et al. (1999) reported ECG monitoring, and of these, none reported clinically significant ECG abnormalities.

2. Guanfacine (Tenex). Guanfacine is the generic name for the antihypertensive drug Tenex. It has been shown to be effective in reducing parent-rated behavior problems associated with $\mathrm{ADHD}$ at doses beginning at $0.5 \mathrm{mg} /$ day and increasing to an average dose of $3.2 \mathrm{mg} /$ day, given in 3-4 divided doses throughout the day (Hunt, Arnsten, \& Asbell, 1995). Guanfacine did not result in significant side effects in children with ADHD, although some sedation and drowsiness were reported for a small proportion of the sample and about $25 \%$ of the children in this study reported headaches and stomachaches during the early part of the one-month trial (Hunt et al., 1995).

\section{Decision-Making in Selecting a Medication}

Considering the number of drugs that have been used to treat ADHD with some effectiveness, a reasonable question is how physicians go about making decisions regarding medication for ADHD. Many factors influence the decisions of individual physicians. Based on clinical experience and reviews of the research, the following steps are recommended for making choices regarding medication.

Barring any contraindications, the first choice of medication usually should be Ritalin because of its greater documentation in research, proven efficacy across a wide age range, more dose-response information, and wider margin of safety than the other two classes of medications reviewed here (antidepressants and antihypertensives).

Because a child's failure to respond to one stimulant, such as Ritalin, does not mean that he or she might not benefit from another stimulant (Elia \& Rapoport, 1991), a trial of Adderrall is recommended as the next step. This drug has 
TABLE 3

The Antihypertensives: Drugs, Clinical Effects, Contraindications, Dosing information, Peak Effects, Halflife, and Side Effects

\begin{tabular}{lll} 
Drug Feature & Clonidine & Guanfacine \\
Brand Name & Catapres & Tenex \\
\hline $\begin{array}{l}\text { Areas Shown to be } \\
\text { Improved }\end{array}$ & Parent, teacher, clinician ratings & Parent ratings \\
$\begin{array}{l}\text { Contraindications to Use } \\
\text { Recommended Starting/ }\end{array}$ & None reported & None reported \\
$\begin{array}{l}\text { Maximum Dose } \\
\text { Duration of Action/ }\end{array}$ & Unknown & $0.5 \mathrm{mg} /$ day \\
$\begin{array}{l}\text { Peak Effects } \\
\text { Half-Life }\end{array}$ & $17-41$ hours & $4 \mathrm{mg} /$ day in $0.5 \mathrm{mg}$ increments \\
Common Side Effects & Sedation, irritability, blood pressure/ & Unknown \\
\hline
\end{tabular}

been shown to be just as effective as Ritalin and may not have as many side effects as Dexedrine (e.g., Swanson et al., 1998a).

If Adderall is unsuccessful, a trial of Dexedrine could be considered, with the understanding that its potency is higher than both Adderall and Ritalin - that is, a lower dose is required to influence behavior change and cause side effects. If these medications are not effective, a trial of Cylert could be considered. The risk of hepatic toxicity of this medication, however, requires closer monitoring and periodic assessment of liver functioning, making it a less benign medication than the other stimulants.

If none of the stimulant medications are effective, a tricyclic antidepressant (e.g., desipramine or imipramine), SSRI (Prozac), or some other antidepressant (Wellbutrin) should be considered. Finally, some clinicians elect for a trial of one of the antihypertensive agents (e.g., clonidine or guanfacine). If these, too, fail, pharmacotherapy may have to be discontinued for at least one year, if not altogether eliminated from consideration.

Children younger than 6 years of age who have a poor response to stimulants might respond positively in later years (after the age of 6). Perhaps more important than the selection of specific medication(s) - a decision that is likely influenced by many factors-is that the evaluation of whether the drug is effective take place in a systematic and structured fashion.

\section{Best Practices for the Assessment of Drug Effects In Children Diagnosed with ADHD}

Once parents and teachers of children with ADHD establish a basic understanding of psychopharmacology and knowledge of the kinds of drugs typically used to treat ADHD, they should be made aware of well established procedures for effectively evaluating the efficacy of medication. These procedures and recommended guidelines will be discussed next.

\section{Ensuring Proper Assessment and Diagnosis.}

The first step in properly managing behavioral problems through medication is to make sure that the child has had an adequate physical and psychological examination. Guidelines for the proper assessment of ADHD include clinical interviews with parents and children, completion of standardized behavior rating scales by parents and teachers, direct observation, and physical examination (Dulcan \& Benson, 1997). Doctors, parents, and teachers involved with assessing ADHD should be prepared to commit the time necessary to complete the various components of this assessment. A proper assessment must include information from several different settings (home, school, etc.) and should be conducted by a professional trained explicitly in the diagnosis of ADHD. 
Although clinicians vary with respect to the specific instruments used to assess ADHD, we recommend the following, all of which are available in parent and teacher formats and are among the more widely used and well standardized: Child Behavior Checklist/Teacher Report Form (Achenbach \& Edelbrock, 1993); Behavioral Assessment System for Children (Reynolds \& Kamphaus, 1994), ADHD-IV Rating Scale (DuPaul, Power, Anastopoulos, \& Reid, 1999), Disruptive Behavior Rating Scale (Barkley \& Murphy, 1998); and Revised Conners Rating Scales (Conners, 1997). In addition, semistructured clinical interviews, such as the Parental Interview Form (Barkley \& Murphy, 1998), are useful for gathering detailed information regarding the child's behavioral problems. It is important to note, however, that, given the overlap between symptoms of ADHD and other kinds of behavioral and emotional problems, assessment and diagnosis of this disorder rarely are straightforward and cannot be conducted using rating scales alone.

Although, again, individual clinicians vary as to the extent of medical evaluation necessary for each individual patient, the following are general recommendations for things that should be included in an initial work-up. Some components of the initial medical evaluation may be different, depending on the type of medication to be selected.

First, height and weight always should be recorded, and, if possible, earlier measurements obtained so the child's position and former trajectory on a growth velocity curve can be estimated. This makes it easier to evaluate any subsequent change in growth rate, which is especially important if stimulant drugs are to be used.

Possible cardiological abnormalities should be evaluated, and blood pressure and pulse taken. Monitoring of cardiac functioning is especially important if the child is to be prescribed antidepressant medication. The child's previous eating and sleeping patterns have to be established, as these are areas in which side effects are likely to arise with many of the medications.

Ideally, pretreatment levels of potential behavioral side effects should be obtained by administering the Side Effects Rating Scale (Barkley \& Murphy, 1998) at this time, as many clinic-referred children show behavioral/emotional problems before beginning medication. Without monitoring, these preexisting conditions could easily be confused as side effects during the subsequent trial.

Finally, a careful history should be taken for evidence of possible seizure disorders and tics, with follow-up investigation if indicated. Other laboratory tests (CBC, liver function tests) are needed only as baseline data or as part of a routine physical evaluation. They have no routine specific application in preparation for prescribing the medications discussed in this article, unless Cylert is to be used.

\section{Issues in the Decision to Use Medication}

Even after a conclusive diagnosis has been established and a thorough medical evaluation completed, the decision to use medication with children who have ADHD should not be made without considerable forethought. Parents and teachers should keep in mind that, although medication has been shown to be most effective in managing these problems, considerable improvements can be achieved through properly implemented psychological/psychosocial interventions (e.g., MTA Cooperative Group, 1999).

The following rules/questions might be useful in helping parents and teachers make informed decisions about the use of medication for behavior problems with children who have ADHD. These are intended only as rules of thumb, and all parties involved clearly should remain flexible regarding the unique needs and circumstances of each case.

1. How old is the child? Pharmacotherapy may be less effective or lead to more severe side effects in children below 4 years of age (e.g., Firestone, Musten, Pisterman, Mercer, \& Bennett, 1998) and therefore is not usually recommended. Generally, however, little is known about the safety and efficacy of medication for ADHD in this age range. Research currently is being conducted to address this lack of information.

2. Have other therapies been used? If this is the family's initial contact with the professional, prescription of medication might be postponed until other interventions (e.g., parent training in child management skills or psychosocial treatment for the child) have been attempted because, under some circumstances, these interventions can be useful for reducing ADHD-related problems (MTA Collaborative Group, 1999). Alternatively, if the family or child is unable to participate in behavioral/psychosocial interventions, for whatever reason, medication might be the most viable initial treatment.

3. How severe are the child's current symptoms? In some cases, the child's behavior is so unmanageable or distressing to the family that medication may be the fastest and most effective manner of dealing with the crisis until other forms of treatment can commence. Once the child progresses with other therapies, some effort can be made to reduce or terminate the medication, although this is not always possible.

4. Can the family afford the medication and associated costs (e.g., follow-up visits)? Long-term compliance rates typically are poor and may be especially problematic among families with limited financial resources. It also may be difficult for these families to participate fully in alternative treatments because 
of financial or other constraints, and this also should be taken into consideration

5. Are the parents able to adequately supervise the use of the medications and guard against their abuse? Some assessment of family functioning and parental monitoring should be undertaken to ensure safe and appropriate handling of medications.

6. What is the parent's attitude toward pharmacotherapy? Some parents simply are "anti-drug" and should not be coerced into agreeing to this form of treatment.

7. Does the household include a substance-abusing sibling or drug-abusing parent? If so, stimulant medication should not be prescribed because of the high risk for its illicit use or sale. A sustained-release stimulant medication might be considered, as this type has been shown to have lower potential for abuse (e.g., Kollins, Rush, Pazzaglia, \& Ali, 1999). Cylert also might be considered because it seems to have little or no street value or potential for abuse. Finally, alternative medications such as the antidepressants or hypotensive agents might be considered.

8. Does the child have any history of tics, psychosis, or thought disorder? If so, the stimulants should be used with more caution, lower starting doses, and more careful monitoring. For some children with these disorders, the stimulants are contraindicated because they exacerbate such difficulties. Other nonstimulant medications should be considered.

9. Is the child highly anxious, fearful, or likely to complain of psychosomatic disturbances? Children with these characteristics may be less likely to respond positively to stimulant medications and may have a better response to antidepressant or antihypertensive medications.

10. Does the physician have the time to monitor medication effects properly? In addition to an initial assessment of drug efficacy and establishing the optimal dosage, periodic reassessment of drug response is necessary to maximize effects.

11. How does the child feel about medication and its alternatives? With older children and adolescents, the medication has to be discussed with them, and its rationale fully explained. If children are "anti-drug" or oppositional, they may resist efforts to use the medication (e.g., refuse to swallow the pill).

12. Is this child or adolescent involved in competitive sports in which urine screens for illicit drug use are routine? If so, the clinician should discuss this with the parents, as some children may be disqualified from participating in competitive sports as a result of taking Ritalin immediately prior to or during competitive events.
13. Is the older adolescent being considered for medication treatment planning to enter the military? In a number of reported instances, teenagers planning to enlist in the U.S. military have been denied admission because of a history of having ADHD and, in particular, of having been treated with stimulant medication within the past few years. Again, clinicians should discuss this issue with parents and the adolescent before initiating stimulant-medication treatment. Information from the branches of the military suggests that use of medication in childhood may not disqualify a young adult from military service but taking such medication within a few years of enlistment could do so (Hathaway, 1997).

Once these questions have been addressed adequately and a decision has been made to prescribe medication, the next step is to begin an appropriate dosing regimen and establish a systematic framework in which to evaluate the drug effects. The methods that practicing clinicians use to monitor response to medication vary widely in content and quality. Unfortunately, all too frequently, titration of dosage and long-term assessment of efficacy are based solely on the subjective reports of parents, thereby increasing the chances of erroneous decisions. Indeed, the most appropriate clinical dosage for a child cannot be established adequately without school-based information, which can be obtained directly or via the parent, teacher, and standardized rating scales.

Bearing heavily on this issue are results from the MTA study. This study demonstrated that structured management of medication, involving monthly visits to the clinic and collection of objective data from parents and teachers on a regular basis, was significantly more effective in treating ADHD than an approach that was less structured and involved less frequent contact between the physician and the parent and child (MTA Cooperative Group, 1999). To emphasize - the role of teachers and parents and their communication with physicians was of utmost importance in the optimal treatment of children with ADHD.

The medication management group from the MTA study also went through a structured procedure for determining the optimal dose of medication for each child. The superiority of this approach highlights the need for objective data regarding changes in a child's behavior to be collected across several doses given the frequently unique and idiosyncratic reactions of children to these drugs. Under ideal circumstances, a child's optimal dose should be established in the context of a double-blind, placebo-controlled assessment paradigm that includes multiple measures collected across several settings (home, school, and clinic).

"Double-blind" refers to the fact that the child and his or her parents and teachers do not know whether they are 
receiving actual medication or a capsule with no medication (placebo) on a day-to-day or week-to-week basis. This type of evaluation involves not only the aggregation of objective, quantitative data regarding a child's treatment response but also the use of a placebo control wherein teachers, parents, and children do not know the dosage being administered (Barkley, Fischer, Newby, \& Breen, 1988). In addition, it is helpful for the parents and teachers to complete a weekly Side-Effects Questionnaire (e.g., Barkley \& Murphy, 1998).

There is a high likelihood of apparent "practice effects" on these rating scales between their first and second, and possibly later, administrations. Many parent and teacher rating scales show significant declines in scores between their first and second administrations even without intervening treatment. Clinicians who give the scales once, begin drug treatment, and then give them again a week or two later are likely to confuse the drug effects with these practice effects, concluding that the medication or that dose of it was helpful when it might not have been. Clinicians using these scales should give them twice before using them in drug trials and use the second administration as the baseline against which to measure changes resulting from medication trials.

Figure 2 outlines recommended steps in a standard double-blind placebo medication assessment for stimulant drugs. These procedures are appropriate only for the stimulant drugs, whose time course of action and half-life are quite short. The procedures for conducting systematic medication evaluations for drugs other than stimulants are somewhat more challenging for a number of reasons. As such, we will structure our discussion of evaluating drug effects primarily in the context of stimulant medications.

More detailed descriptions of double-blind protocols can be found in the research literature (e.g., Fischer \& Newby, 1991), and we present the basic steps. Once children have been properly assessed and a prescription has been written, it is important to communicate with a pharmacist who is willing to prepare capsules for the double-blind experiment. In our experience, most pharmacists are more than willing to assist in such an evaluation. Usually, the pharmacist will prepare 3 weeks' worth of medication into three separate containers, marked "Week 1," "Week 2," and "Week 3." Although not as comprehensive, a trial involving a relatively high dose, a relatively low dose, and placebo is helpful in determining optimal response. For example, a physician could decide to evaluate the effects of $5 \mathrm{mg}$ Ritalin three times daily, $10 \mathrm{mg}$ Ritalin three times daily, and placebo. In this case, the pharmacist would prepare one pill bottle with 21 capsules (3/day for 7 days), each containing $5 \mathrm{mg}$ Ritalin and a filler (usually dextrose), another bottle with 15 capsules each containing $10 \mathrm{mg}$ Ritalin and filler, and one bottle containing 21 capsules with only filler.

The capsules should be opaque and small enough for a child to swallow easily (in our experience, size 2 capsules, about 1/4 inches diameter and 3/4 inches length, work well). The pharmacist then randomly decides which bottle will be administered during which week. Ideally, only the pharmacist should be aware of this information and should break the blind at the end of the evaluation. In the event of medical problems or significant side effects, the blind should be broken immediately.

During the initial assessment and, preferably, at least one more time prior to the beginning of the first week of the trial, parents and teachers should complete the forms described above. Once the individual coordinating the evaluation (e.g., physician, psychologist) has completed and gathered this baseline information, the trial may commence. Parents should administer one capsule to their children two or three times each day at the times the physician specifies. At the end of each week, parents and teachers should complete the behavior-ratings and side-effects questionnaires and return them to the coordinating individual. This should be completed for all 3 weeks. At the end of the third week, the person coordinating the evaluation should graph the information collected from parents and teachers as shown in Figure 3.

At this time, the coordinator and the physician should make a judgment about which dose is best for the child. In this case, the best dose would be whatever was prescribed in week 3 -the ratings of problem behavior were lowest and the side effects were not different from the other weeks. At this point, the blind should be broken and the pharmacist should report the information to all parties. Sophisticated techniques for graphing and statistically analyzing data of the sort presented in Figure 3 have been described (Swanson et al., 1998b).

Several points regarding the double-blind medication assessment are worth noting.

- First, if feasible, a third dose of medication may be evaluated. The procedures would be identical, thus extending the trial by one week.

- Second, if the best dose was placebo, this might indicate that the child may not respond well to the medication in question. Alternatively, it may be necessary to titrate the dosage somewhat to determine if another dose (perhaps one in between the lowest dose and the placebo) would be effective.

- Finally, the evaluation as described is appropriate only for the comparatively short-acting stimulants. Longeracting compounds, such as the antidepressants, usually involve continuous administration of active medication or placebo for several weeks, at which time objective measures are collected and decisions about efficacy can be made. 


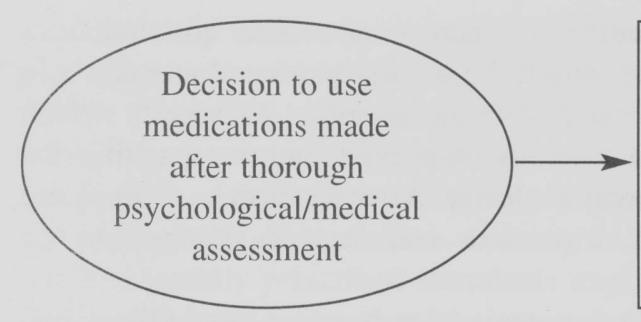

- Prescriptions obtained

- Pharmacist contacted

- Capsules prepared

- Objective measures prepared

- Baseline data collected (including side effects) on at least two occasions

Prior to initiating trial

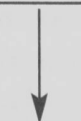

- Dose Level 1 administered (usually two or three times daily)

- Objective measures (parent/teacher) collected at week's end

- Side effects data collected at week's end

Week One

- Dose Level 2 administered (daily)

- Objective measures (parent/teacher) collected at week's end

- Side effects data collected at week's end

Week Two

- Dose Level 3 administered (daily)

- Objective measures (parent/teacher) collected at week's end

- Side effects data collected

Week Three

At the end of

- Data compared

- Decision made regarding efficacy to maximize clinical effects/minimize side effects

- Blind broken

- Decision made to further titrate, prescribe, or discontinue medication

Week Three 


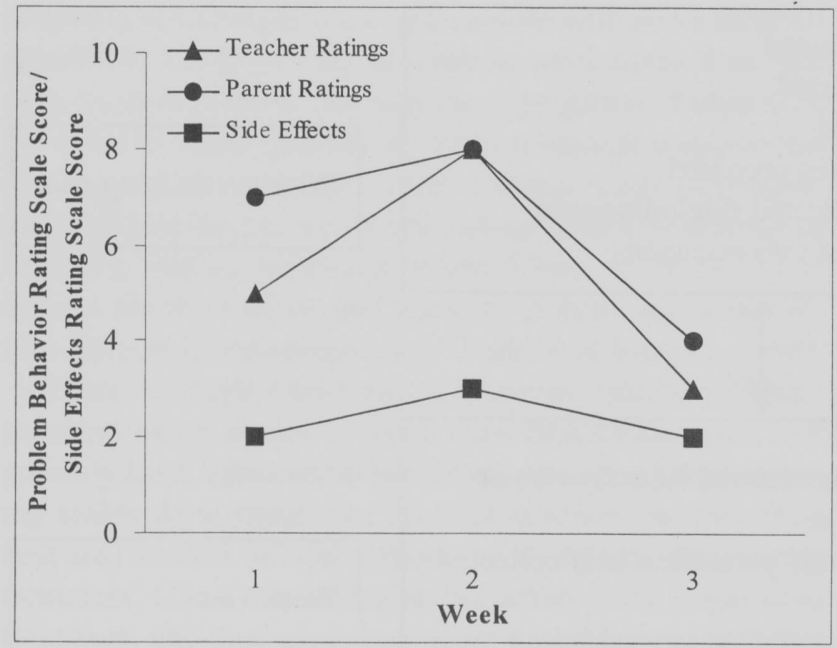

\section{FIGURE 3 \\ Hypothetical Results from a Double-blind, Placebo-controlled Medication Evaluation with two doses of Drug and Placebo}

Once a child's optimal dosage is established, some, preferably all, of the above standardized measures should be collected periodically from parents and teachers to evaluate the need for dosage adjustments or the onset of side-effects. Recall that the best effects were observed in the MTA study when contact was made monthly and objective data were gathered at this point. If this is not feasible, information on side effects, at the least, should be collected monthly to ensure the absence of any adverse drug effects.

Parents should be informed in advance about the presenting symptoms and any serious side effects associated with the medication (see Tables 1, 2, and 3). For children receiving Cylert, blood should be drawn for liver function tests at 6-month intervals, or whenever symptoms prompt suspicions, given the findings that this drug rarely and idiosyncratically affects liver functions adversely. At similar intervals, children receiving tricyclic antidepressants should be evaluated for cardiac functioning.

During the course of pharmacotherapy, parents might report that formerly effective doses are no longer having positive effects. Caution is warranted before deciding to increase the level of medication. In the absence of precipitating stressful events, family turmoil, or other medical events (such as the use of other medications), the current dosage indeed might have become less effective. Careful questioning of the parent as to the ways in which the child's behavior is different or worse can be useful in making the decision. In addition, the child's teacher should be contacted to ascertain whether his or her functioning is also impaired in the school setting. The parent and teacher questionnaires discussed above should be administered and compared to previously collected data in an effort to specify which behaviors have actually worsened and to quantify the amount of behavioral change. After this is done, if there are no side effects, a cautious increment in dosage may be attempted.

Once ADHD symptoms have been managed effectively, the question of when to discontinue treatment may arise. No firm guidelines are in place regarding when to discontinue pharmacological treatment, other than a determination that it no longer seems to be necessary. Up to $20 \%$ of children may be able to have medication stopped after a year or so. These drugs do not necessarily have to be discontinued at the onset of puberty as was once believed, as their efficacy with adolescents and adults has been well established (Smith, Pelham, Gnagy, \& Yudell, 1998; Spencer et al., 1995). Further, the practice of "medication holidays" and taking children off medication during the summer months is generally not necessary because these drugs do not have significant effects on growth (e.g., Zeiner, 1995). In fact, doing so is likely to result in impaired functioning in activities in which a child may be engaged during these times, such as sports, hobbies, and social interactions.

\section{Other Issues in the Pharmacological Treatment Of Children with ADHD}

Parents, teachers, and other professionals who work with children who might be taking medication for behavior problems also should recognize some of the limitations in our understanding of how these drugs work and some areas that require further research. We will comment briefly on four important issues in this area: predicting individual response to medication, evaluating consumer satisfaction with medication, using medication with younger children, and assessing the long-term effects of medication use with children who have ADHD.

\section{Predicting Individual Response to Medication}

As noted, different children respond differently to different medications. Moreover, different types of behavior exhibited by the same child can be influenced differently by the same doses of the same medication. As such, an important issue in the proper clinical management of child behavior problems is to determine which medications are most likely to be effective for which children, and for which behaviors.

More research by far has been conducted on which children respond to stimulant medications compared to the other types of drugs discussed. Very little is known about which children with ADHD are likely to benefit from drugs other than stimulants, although Wellbutrin might be particularly 
well suited for children and adolescents who have conduct and substance use problems in addition to their ADHD (Riggs et al., 1998). Stimulant medication has been shown to be effective in reducing problem behavior for approximately $75 \%$ of children to whom they are prescribed (Swanson et al., 1993). Nevertheless, as many as $20 \%$ to $30 \%$ of children initially prescribed stimulants might not display a positive response to these medications and might even show an increase in behavior problems.

As noted, our understanding is limited as to which children respond well to drugs other than stimulants. A variety of factors, however, have been proposed to distinguish children with ADHD who would respond favorably to stimulant medications (responders) from those who would not (nonresponders) including: psychophysiological factors, neurological variables, familial characteristics, demographic/ sociological factors, diagnostic categories, rating-scale scores, psychological profiles, and behavioral characteristics (Barkley, 1976). Behavioral and psychophysiological measures related to attention span typically are the most reliable predictors of improvement during stimulant-drug treatment. The greater a child's inattention, the better is his or her reaction to medication (the more pronounced effect on attention span; Rapport, Stoner, DuPaul, Birmingham, \& Tucker, 1985).

Some studies also have found that the quality of the relationship between parent and child was a good predictor of drug response. The better the mother-child relationship, the greater is the response to medication. This is related to the findings reported earlier that, for many children, the medication produces positive changes in the behavior of children and their mothers alike. Mothers who are more appreciative and rewarding of these initial positive changes in their children's behavior while on stimulants possibly produce further gains associated with treatment. In support of this, Cunningham and Barkley demonstrated that mothers who were more interactive with their children and more rewarding of child compliance prior to pharmacotherapy had children who showed greater positive changes in behavior as a result of treatment with medication (cf. Barkley, 1981).

Higher levels of restless behavior (e.g., hyperactivity), poor motor coordination, younger age, and the absence of symptoms of overt emotional disorder predicted better stimulant response among a large sample of children with ADHD (Taylor, 1986). Similar reports suggest that children who are more anxious or depressed according to parent and/or teacher ratings (e.g, Conners Rating Scales) have a poorer response to stimulant medications and are less likely to exhibit "normalized" behavior as a result of treatment (e.g., Pliszka, 1989).

A later study suggested that measures of academic performance are most useful as targets to predict which children will respond to Ritalin at which doses (Denney \& Rapport, 1999). Those authors argued that, when proper statistical techniques are used, the ability of baseline scores of attention and hyperactivity (such as predicted by Taylor, 1986) to predict response to medication is decreased substantially. As such, they recommended that academic performance be used to adjust dose levels of Ritalin when children are functioning at or below a specified level of impairment. Response to medication in children who do not show the same level of academic impairment should be evaluated using other, more specific, domains of functioning, such as attention and hyperactivity (Denney \& Rapport, 1999).

For clinical purposes, the current evidence still suggests that the younger (but still school-age), more inattentive, less coordinated, more hyperactive, less anxious, and less intellectually delayed a child may be, and the better the parental management and involvement in care of the child, the better the response to stimulant treatment. Moreover, academic performance that is impaired substantially could be an even better predictor of response to stimulant medication. As noted previously, predicting response of ADHD symptoms to the other classes of medication is difficult at present and warrants more research.

\section{Consumer Satisfaction}

One might assume that the widespread use of medication (especially stimulants) with children who have ADHD subsumes relatively high consumer satisfaction with this approach to treatment. Relatively few studies, however, have been conducted to document whether parents and teachers are indeed satisfied with pharmacotherapy for children with ADHD. One study revealed that parents of children with ADHD initially rated behavioral intervention as more acceptable than the use of medication for ADHD (Liu, Robin, Brenner, \& Eastman, 1991). This study, however, was based on parents' reading a description of a hypothetical case and the judgments were not based on direct experience with the interventions. Follow-up data in the same study revealed that parents' acceptability of Ritalin increased as a function of their knowledge about ADHD (Liu et al., 1991). Recall also that parents in the MTA study reported higher levels of satisfaction with treatment when a behavioral/psychosocial intervention was included (MTA Collaborative Group, 1999).

Other studies have reported that parents typically are pleased with the use of medication in treating ADHD in children, but that these perceptions often are not congruent with the attitudes of the children taking the medication. For example, one study reported that in more than $25 \%$ of the cases in which children were treated with Ritalin, parents reported a favorable response to the drug whereas children reported a negative response (Efron, Jarman, \& Barker, 
1998). The subjective reports of children, especially those of very young children, are likely not as reliable as reports from parents and teachers (e.g., Sleator, Ullmann, \& von Neumann, 1982). Nevertheless, given the frequency with which medication is used to manage ADHD and other behavior and emotional problems in children, more studies have to be conducted to determine how the children themselves perceive this approach to treatment and whether their perceptions are of clinical importance.

\section{Using Medication with Younger Children}

A study by Zito et al. (2000) documented the growing use of prescription medication, especially stimulant drugs, for use with preschool children. This pattern is particularly controversial because the package inserts and labeling for these medications (especially Ritalin) do not describe their use for children in this age range. The federal government has indicated that well controlled, large-scale research into the effects of these and other kinds of drugs in very young children is a top research priority.

Although a handful of studies have investigated the efficacy of Ritalin in preschool children (e.g., Barkley, 1988), the results of these studies generally have shown that the drug is not as efficacious for managing problems associated with ADHD. In addition to the need for studies that document the safety and efficacy of using medication with ADHD preschoolers who have ADHD, information is lacking on how the use of stimulants and other drugs may impact development of the nervous system, which is still in its important formative stages during the preschool years.

\section{Assessing Long-term Effects}

Perhaps one of the more controversial issues in treating of children with ADHD is the long-term impact of pharmacological approaches. As noted, the longest systematic studies of use of medication with children who have ADHD noted continued clinical benefits 14 months after initiating treatment (MTA study). Other studies have noted that the use of stimulant medication may have long-term protective effects against the development of other kinds of problems, such as substance abuse (e.g., Biederman et al., 1999). Although several other longitudinal studies of children with ADHD are ongoing (e.g., Mannuzza et al., 1998; Barkley et al., 1991), specific long-term effects of use of medication have not been evaluated systematically in these samples.

Another possible long-term side effect specific to the use of stimulant medications, though unlikely, is the suppression of height and weight gain. Early reports indicated that both Ritalin and Dexedrine produced this effect (e.g., Safer, Allen, \& Barr, 1972). Later studies have found this to be a dose-related phenomenon, more prevalent with Dexedrine, and to occur primarily within the first year of treatment. The loss in weight typically is minimal ( $1 \mathrm{~kg} / 2.2 \mathrm{lbs}$. or less), and growth or habituation to this effect seem to rebound, therefore yielding no appreciable effect on eventual adult height or weight (e.g., Zeiner, 1995).

Effects on growth are thought to be secondary to suppression of appetite and stomach distress produced by these drugs, although several studies have indicated that stimulants might have some direct effects on growth hormone levels in the blood (Reeve \& Garfinkel, 1991). Thus, a reasonable conclusion is that any suppression in growth is typically minor, is a relatively transient side effect of the first year or so of treatment, and has no significant effect on eventual adult height or weight for the vast majority of children with ADHD.

Evidence indicates that children with ADHD may be somewhat smaller than typical children prior to puberty and catch up with typical peers during adolescence, yet growth delay is associated with the disorder and not with treatment using stimulant (Spencer et al., 1996). As always with group studies, however, a few individuals within the group have more serious weight loss as a function of stimulant treatment. Being so few in number, they may be averaged out of the resulting mean statistics. Consequently, the clinician still has to monitor weight and height periodically in children who receive stimulant medications and to alter dosage scheduling if clinically significant changes occur in these growth parameters as a function of treatments using stimulants.

Again, given the comparative frequency with which other kinds of medication (e.g., antidepressants, antihypertensive agents) are prescribed for ADHD and are studied formally, little is known about the long-term effects of using these kinds of medication with children with ADHD. Future research has to focus on the effects of these drugs, the combination of these and other drugs, and the combination of medication and behavioral interventions, especially as the use of multiple prescription medications becomes more widespread in managing childhood behavior problems.

\section{CONCLUSIONS}

The use of psychoactive medication or its combination with behavioral interventions has been shown consistently to be the most effective approach to managing ADHD. The manner in which the medication is used, however, is critical to optimize clinical efficacy and minimize side effects. Especially important is the regular input of teachers and parents. The MTA Collaborative Study (1999) noted that "systematic and regular feedback from teachers [does] not seem to be part of routine pediatric ADHD treatment practices, and may have enhanced the effectiveness of [the study's] medication management" (p. 1081). Implicit also in this study were structured, monthly meetings and communication 
between parents and health-care providers, a practice often not followed in the routine treatment of ADHD. We hope that better understanding of some of the relevant issues involved with use of medication for ADHD will facilitate communication among teachers, parents, and physicians in a manner that maximizes the chances for effective treatment.

\section{REFERENCES}

Achenbach, T.M., \& Edelbrock, C.S. (1991). Child behavior checklist and youth self report. Burlington, VT: Author.

Adler, L.A., Resnick, S., Kunz, M., \& Devinsky, O. (1995). Open-label trial of venlafaxine in adults with attention deficit disorder. Psychopharmacology Bulletin, 31(4), 785-788.

Ahmann, P.A., Waltonen, S.J., Olson, K.A., Theye, F.W., Van Erem, A.J., \& LaPlant, R.J. (1993). Placebo-controlled evaluation of Ritalin side effects. Pediatrics, 91(6), 1101-1106.

American Psychiatric Association. (1994). Diagnostic and statistical manual of mental disorders, 4th ed. Washington, DC: American Psychiatric Press.

Barkley, R.A. (1998). Attention-deficit hyperactivity disorder: A handbook for diagnosis and treatment. New York: Guilford.

Barkley, R.A. (1976). Predicting the response of hyperkinetic children to stimulant drugs: A review. Journal of Abnormal Child Psychology, 4(4), 327-348.

Barkley, R.A. (1981). Hyperactive children: A handbook for diagnosis and treatment. New York: Guilford.

Barkley, R.A. (1988). The effects of methylphenidate on the interactions of preschool ADHD children with their mothers. Journal of the American Academy of Child \& Adolescent Psychiatry, 27(3), 336-341.

Barkley, R.A., \& Cunningham, C.E. (1979). The effects of methylphenidate on the mother-child interactions of hyperactive children. Archives of General Psychiatry, 36(2), 201-208.

Barkley, R.A., Fischer, M., Edelbrock, C., Smallish, L. (1991). The adolescent outcome of hyperactive children diagnosed by research criteriaIII. Mother-child interactions, family conflicts and maternal psychopathology. Journal of Child Psychology \& Psychiatry, 32(2), 233-255.

Barkley R.A., Fischer, M., Newby, R.F., \& Breen, M.J. (1988). Development of a multi-method clinical protocol for assessing stimulant drug responses in ADHD children. Journal of Clinical Child Psychology, $17(1), 14-24$.

Barkley, R.A., \& Murphy, K.R. (1998). Attention-deficit hyperactivity disorder: A clinical workbook. New York: Guilford.

Barrickman, L., Noyes, R., Kuperman, S., Schumacher, E., \& Verda, M. (1991). Treatment of ADHD with fluoxetine: A preliminary trial. Journal of the American Academy of Child \& Adolescent Psychiatry, 30(5), $762-767$.

Barrickman, L.L., Perry, P.J., Allen, A.J., Kuperman, S., Arndt, S.V., Herrmann, K.J., \& Schumacher, E. (1995). Bupropion versus methylphenidate in the treatment of attention-deficit hyperactivity disorder. Journal of the American Academy of Child \& Adolescent Psychiatry, 34(5), 649-657.

Biederman, J., Baldessarini, R.J., Wright, V., Knee, D., \& Harmatz, J.S. (1989). A double-blind placebo controlled study of desipramine in the treatment of ADD: I. Efficacy. Journal of the American Academy of Child \& Adolescent Psychiatry, 28(5), 777-784.

Biederman, J., Wilens, T., Mick, E., Spencer, T., \& Faraone, S.V. (1999). Pharmacotherapy of attention-deficit/hyperactivity disorder reduces risk for substance use disorder. Pediatrics, 104(2), e20.
Birmaher, B., Greenhill, L.L., Cooper, T.B., Fried, J., \& Maminski, B. (1989). Sustained release methylphenidate: Pharmacokinetic studies in ADDH males. Journal of the American Academy of Child \& Adolescent Psychiatry, 28(5), 768-772.

Bukstein, O.G., \& Kolko, D.J. (1998). Effects of methylphenidate on aggressive urban children with attention deficit hyperactivity disorder. Journal of Clinical Child Psychology, 27(3), 340-351.

Cantwell, D.P., Swanson, J., \& Connor, D.F. (1997). Case study: Adverse response to clonidine. Journal of the American Academy of Child \& Adolescent Psychiatry, 36(4), 539-544.

Connor, D.F., Fletcher, K.E., \& Swanson, J.M. (1999). A meta-analysis of clonidine for symptoms of attention deficit hyperactivity disorder. Journal of the American Academy of Child \& Adolescent Psychiatry, 38(12), 1551-1559.

Connor, D.F., Barkley, R.A., \& Davis, H.T. (2000). A pilot study of methylphenidate, clonidine, or the combination in ADHD comorbid with aggressive oppositional defiant or conduct disorder. Clinical Pediatrics, 39(1), 15-25.

Conners, C.K. (1997). Conners rating scales-Revised. North Tonawanda, NY: Multi-Health Systems.

Conners, C.K., Casat, C.D., Gualtieri, C.T., Weller, E., Reader, M., Reiss, A., Weller, R.A., Khayrallah, M., \& Ascher, J. (1996). Buproprion hydrochloride in attention deficit disorder with hyperactivity. Journal of the American Academy of Child \& Adolescent Psychiatry, 34(10), 1314-1321.

Conners, C.K. \& Taylor, E. (1980). Pemoline, methylphenidate, and placebo in children with minimal brain dysfunction. Archives of General Psychiatry, 37(8), 922-930.

Denney, C.B. \& Rapport, M.D. (1999). Predicting methylphenidate response in children with ADHD: Theoretical, empirical, and conceptual models. Journal of the American Academy of Child \& Adolescent Psychiatry, 38(4), 393-401.

Douglas, V.I., Barr, R.G., Desilets, J., \& Sherman, E. (1995). Do high doses of stimulants impair flexible thinking in attention-deficit hyperactivity disorder? Journal of the American Academy of Child \& Adolescent Psychiatry, 34(7), 877-885.

Dulcan, M.K. \& Benson, R.S. (1997). AACAP Official Action. Summary of the practice parameters for the assessment and treatment of children, adolescents, and adults with ADHD. Journal of the American Academy of Child \& Adolescent Psychiatry, 36(9), 1311-1317.

DuPaul, G. J., Power, T. J., Anastopoulos, A. D., \& Reid, R. (1999). The $A D H D$ rating scale-IV: Checklists, norms, and clinical interpretation. New York: Guilford.

Efron, D. Jarman, F.C., \& Barker, M.J. (1998). Child and parent perceptions of stimulant medication treatment in attention deficit hyperactivity disorder. Journal of Paediatric Child Health, 34(3), 288-292.

Efron, D., Jarman, F., \& Barker, M. (1997). Side effects of methylphenidate and dexamphetamine in children with attention deficit hyperactivity disorder: A double-blind crossover trial. Pediatrics, 100(4), 662-666.

Elia J. \& Rapoport J.L. (1991). Ritalin versus dextroamphetamine in ADHD: Both should be tried. In L.L. Greenhill \& B.B. Osmon (Eds), Ritalin: Theory and patient management (pp. 69-74). New York: Mary Ann Liebert.

Elia, J., Welsh, P.A., Gulotta, C.S., \& Rapoport, J.L. (1993). Classroom academic performance: Improvement with both methylphenidate and dextroamphetamine in ADHD boys. Journal of the American Academy of Child \& Adolescent Psychiatry, 34(5), 785-804.

Findling, R.L. (1996). Open-label treatment of comorbid depression and attentional disorders with co-administration of serotonin reuptake inhibitors and psychostimulants in children, adolescents, and adults: A case series. Journal of Child \& Adolescent Psychopharmacology, 6(3), $165-175$. 
Firestone, P., Musten, L.M., Pisterman, S., Mercer, J., \& Bennett, S. (1998). Short-term side effects of stimulant medication are increased in preschool children with attention deficit hyperactivity disorder: A double-blind placebo controlled study. Journal of Child \& Adolescent Psychopharmacology, 8(1), 13-25.

Fischer, M., \& Newby, R.F. (1991). Assessment of stimulant response in ADHD children using a refined multimethod clinical protocol. Journal of Clinical Child Psychology, 20(3), 232-244.

Fletcher, K.E., Fischer, M., Barkley, R.A., \& Smallish, L. (1996). A sequential analysis of the mother-adolescent interactions of ADHD, $\mathrm{ADHD} / \mathrm{ODD}$, and normal teenagers during neutral and conflict discussions. Journal of Abnormal Child Psychology, 24(3), 271-297.

Flicek, M. (1992). Social status of boys with both academic problems and attention-deficit hyperactivity disorder. Journal of Abnormal Child Psychology, 20(4), 353-366.

Gillberg, C., Melander, H., von Knorring, A.L., Janols, L.O., Thernlund, G., Hägglöf, B., Eidevall-Wallin, L., Gustaffson, P., \& Kopp, S. (1997). Long-term stimulant treatment of children with attention deficit hyperactivity disorder symptoms. Archives of General Psychiatry, 54(9), 857-864.

Greenberg, L.M. \& Yellin, A.M. (1975). Blood pressure and pulse changes in hyperactive children treated with imipramine and methylphenidate. American Journal of Psychiatry, 132(12), 1325-1326.

Hathaway, W. (1997). ADHD and the military. ADHD Report, 5(5), 1-6.

Hunt, R.D., Arnsten, A.F.T., \& Asbell, M.D. (1995). An open trial of guanfacine in the treatment of attention deficit hyperactivity disorder. Journal of the American Academy of Child \& Adolescent Psychiatry, 34(1), 50-54.

Jensen, P. S., Kettle, L., Roper, M., Sloan, M.T., Dulcan, M. K., Hoven, C., Bird, H., Bauermeiseter, J. J., \& Payne, J. D. (1999). Are stimulants over-prescribed? Treatment of ADHD in four U.S. communities. Journal of the American Academy of Child and Adolescent Psychiatry, 38(7), 797-804.

Julien, R.M. (1998). A primer of drug action, 8th ed. New York: W.H. Freeman \& Co.

Kollins, S.H., Rush, C.R., Pazzaglia, P.J., \& Ali, J.A. (1998). Comparison of acute behavioral effects of sustained-release and immediate-release methylphenidate. Experimental \& Clinical Psychopharmacology, 6(4), 367-374.

Lahey, B., Applegate, B., McBurnett, K., Biederman, J., Greenhill, L., Hynd, G.W., Barkley, R.A., Newcorn, J., Jensen, P., Richters, J., et al. (1994). DSM-IV field trials for attention deficit hyperactivity disorder in children and adolescents. American Journal of Psychiatry, 151(11), 1673-1685.

Lavigne, J., Gibbons, R. D., Christoffel, K.K., Arend, R., Rosenbaum, D., Binns, H., Dawson, N., Sobel, H., \& Isaacs, C. (1996). Prevalence rates and correlates of psychiatric disorders among preschool children. Journal of the American Academy of Child \& Adolescent Psychiatry, 35(2), 204-214

Liu, C., Robin, A.L., Brenner, S., \& Eastman, J. (1991). Social acceptability of methylphenidate and behavior modification for treating attention deficit hyperactivity disorder. Pediatrics, 88(3), 560-565.

Mannuzza, S., Klein, R.G., Bessler, A., Malloy, P., \& LaPadula, M. (1998). Adult psychiatric status of hyperactive boys grown up. American Journal of Psychiatry, 155(4), 493-498.

Manos, M.J., Short, E.J., \& Findling, R.L. (1999). Differential effectiveness of methylphenidate and Adderall in school-age youths with attention deficit hyperactivity disorder. Journal of the American Academy of Child \& Adolescent Psychiatry, 38(7), 813-819.

MTA Cooperative Group. (1999). A 14-month randomized clinical trial of treatment strategies for attention deficit hyperactivity disorder Archives of General Psychiatry, 56(12), 1073-1086.
Olvera, R.L., Pliszka, S.R., Luh, J., \& Tatum, R. (1996). An open trial of venlafaxine in the treatment of attention deficit hyperactivity disorder in children and adolescents. Journal of Child \& Adolescent Psychopharmacology, 6(4), 241-250.

Otto, M. (2000, March 21). White House launches bid to curb use of psychiatric drugs on children. Washington, DC: Knight-Ridder/Tribune News Service, Washington Bureau.

Pelham, W.E., Aronoff, H.R., Midlam, J.K., Shapiro, C.J., Gnagy, E.M., Chronis, A.M., Onyango, A.N., Forehand, G., Nguyen, A., \& Waxmonsky, J. (1999). A comparison of Ritalin and Adderall: Efficacy and time-course in children with attention deficit hyperactivity disorder. Pediatrics, 103(4), e43.

Pelham, W.E., Greenslade, K.E., Vodde-Hamilton, M., Murphy, D.A., Greenstein, J.J., Gnagy, E.M., Guthrie, K.J., Hoover, M.D., Dahl, R..E. (1990). Relative efficacy of long-acting stimulants on children with attention deficit-hyperactivity disorder: A comparison of standard methylphenidate, sustained-release methylphenidate, sustainedrelease dextroamphetamine, and pemoline. Pediatrics, 86(2), 226-237.

Pelham, W.E., Sturges, J., Hoza, J., Schmidt, C., Bijlsma, J.J., Milich, R., \& Moorer, S. (1987). Sustained release and standard methylphenidate effects on cognitive and social behavior in children with attention deficit disorder. Pediatrics, 80(4), 491-501.

Pelham, W.E., Swanson, J.M., Furman, M.B., \& Schwindt, H. (1995). Pemoline effects on children with ADHD: A time-response by doseresponse analysis on classroom measures. Journal of the American Academy of Child \& Adolescent Psychiatry, 34(11), 1504-1513.

Physician's Desk Reference. (2000). Oradell, NJ: Medical Economics Co.

Pliszka, S.R. (1989). Effect of anxiety on cognition, behavior, and stimulant response in ADHD. Journal of the American Academy of Child and Adolescent Psychiatry, 28(6), 882-887.

Popper, C.W. (1997). Antidepressants in the treatment of attention deficit hyperactivity disorder. Journal of Clinical Psychiatry, 58(Suppl 14), 14-29.

Rapoport, J.L., Quinn, P.O., Bradbard, G., Riddle, D., \& Brooks, E. (1974) Imipramine and methylphenidate treatments of hyperactive boys. Archives of General Psychiatry, 30(6), 789-793.

Rappley, M.D., Mullan, P.B., Alvarez, F.J., Eneli, I.U., Wang, J., \& Gardiner, J.C. (1999). Diagnosis of attention deficit/hyperactivity disorder and use of psychotropic medication in very young children. Archives of Pediatric \& Adolescent Medicine, 153(10), 1039-1045.

Rapport, M.D., DuPaul, G.J., Stoner, G., \& Jones, J.T. (1986). Comparing classroom and clinic measures of attention deficit disorder: Differential, idiosyncratic, and dose-response effects of methylphenidate. Journal of Consulting \& Clinical Psychology, 54(3), 334-341.

Rapport, M.D., Stoner, G., DuPaul, G.J., Birmingham, B.K., \& Tucker, S. (1985). Methylphenidate in hyperactive children: Differential effects of dose on academic, learning, and social behavior. Journal of Abnormal Child Psychology, 13(2), 227-244.

Reeve, E. \& Garfinkel, B. (1991). Neuroendocrine and growth regulation: The role of sympathomimetic medication. In L.L. Greenhill \& B.B. Osmon (Eds.), Ritalin: Theory and patient management (pp. 289300). New York: Mary Ann Liebert.

Reynolds, C. \& Kamphaus, R. (1994). Behavioral assessment system for children. Circle Pines, MN: American Guidance Service.

Riggs, P.D., Leon, S.L., Mikulich, S.K., \& Pottle, L.C. (1998). An open trial of buproprion for ADHD in adolescents with substance use disorders and conduct disorder. Journal of the American Academy of Child \& Adolescent Psychiatry, 37(12), 1271-1278.

Safer D.J., Allen, R.P., \& Barr E. (1972). Depression of growth in hyperactive children on stimulant drugs. New England Journal of Medicine, 287(5), 217-220. 


\section{New Ways of Looking at}

\section{Learning Disabilities}

\section{Connections to Classroom Practice}

Lou Denti, California State University, Monterey Bay

Patricia Tefft-Cousin, Late of Indiana University at Purdue

This text bridges the gap between general and special education pedagogy by including constructivism, humanist, social-cultural, and multicultural points of view.

Through case studies and discussions, you will see students experiencing success using student-centered curriculum approaches, thematic teaching, multi-age grouping, peer-mediated instruction, multicultural curriculum, authentic assessment, and much, much more!

The book includes "thought pieces" presenting main issues and questions brought about by new perspectives. Each thought piece is followed by practical ideas to improve classroom instruction. It also shows how to access perspectives from the students who are being taught. It allows teachers to know how their students learn best and how to plan curriculum for them. You will find a whole new approach to teaching in this new book.

\section{Special Features}

Links constructivism to special education practices

Includes proven classroom ideas

- Addresses diversity issues

- Intended for both special and general classrooms

Pragmatic, easy to use strategies

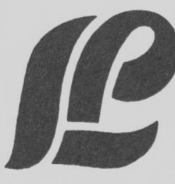

Love Publishing Company

9101 E. Kenyon Ave., Suite 2200

Denver, CO 80237

303-221-7333 o 303-221-7444 (FAX) 
Sallee, F.R., Stiller, R.L., \& Perel, J.M. (1992). Pharmacodynamics of pemoline in attention deficit disorder with hyperactivity. Journal of the American Academy of Child \& Adolescent Psychiatry, 31(2), 244-251.

Sleator, E.K., Ullmann, R.K., \& von Neumann, A. (1982). How do hyperactive children feel about taking stimulants and will they tell the doctor? Clinical Pediatrics, 21(8), 474-479.

Smith, B.H., Pelham, W.E., Gnagy, E., \& Yudell, R.S. (1998). Equivalent effects of stimulant treatment for attention deficit hyperactivity disorder during childhood and adolescence. Journal of the American Academy of Child \& Adolescent Psychiatry, 37(3), 314-321.

Spencer, T.J., Biederman, J., Harding, M., O’Donnell, D., Faraone, S.V., \& Wilens, T.E. (1996). Growth deficits in ADHD children revisited: Evidence for disorder-associated growth delays? Journal of the American Academy of Child \& Adolescent Psychiatry, 35(11), 1460-1469.

Spencer, T., Biederman, J., \& Wilens, T. (1999). Attention-deficit/hyperactivity disorder and comorbidity. Psychiatric Clinics of North America, 46(5), 915-927.

Spencer, T., Wilens, T., Biederman, J., Faraone, S.V., Ablon, S., \& Lapey, K. (1995). A double-blind, crossover comparison of methylphenidate and placebo in adults with childhood-onset attention deficit hyperactivity disorder. Archives of General Psychiatry, 52(6), 434-443.

Sprague, R.L., \& Sleator, E.K. (1977). Methylphenidate in hyperkinetic children: Differences in dose effects on learning and social behavior. Science, 198(4323), 1274-1276.

Spring, C., Yellin, A.M., \& Greenberg, L. (1976). Effects of imipramine and methylphenidate on perceptual-motor performance of hyperactive children. Perceptual \& Motor Skills, 42(43), 459-470.

Swanson, J.M., McBurnett, K., Wigal, T., Pfiffner, L.J., et al. (1993). Effect of stimulant medication on hyperactive children: A review of reviews. Exceptional Children, 60(2), 154-162.

Swanson, J.M., Wigal, S., Greenhill, L.L., Browne, R., Waslik, B., Lerner, M., Williams, L., Flynn, D., Agler, D., Crowley, K., Fineberg, E., Baren, M., \& Cantwell, D.C. (1998a). Analog classroom assessment of Adderall in children with ADHD. Journal of the American Academy of Child \& Adolescent Psychiatry, 37(5), 519-526.
Swanson, J.M., Wigal, S., Udrea, D., Lerner, M., Agler, D., Flynn, D., Fineberg, E., Davies, M., Kardatzke, D., Ram, A, \& Gupta, S. (1998b). Evaluation of individual subjects in the analog classroom setting: I. Examples of graphical and statistical procedures for within-subject ranking of responses to different delivery patterns of methylphenidate. Psychopharmacology Bulletin, 34(4), 825-832.

Tannock, R., Schachar, R.J., Carr, R.P., \& Logan, G.D. (1989). Dose repsonse effects of methylphenidate on academic performance and overt behavior in hyperactive children. Pediatrics, 84(4), 648-657.

Taylor E.A. The overactive child. (1986). Philadelphia: L.P. Lippincott.

Varley, C.K., \& McClellan, J. (1997). Case study: Two additional sudden deaths with tricyclic antidepressants. Journal of the American Academy of Child \& Adolescent Psychiatry, 36(3), 390-394.

Wilens, T.E. (1999). Straight talk about psychiatric medication for kids. New York: Guilford Press.

Wilens, T.E., Biederman, J., Baldessarini, R.J., Geller, B., Schleifer, D., Spencer, T.J., Birmaher, B., \& Goldblatt, A. (1996). Cardiovascular effects of therapeutic doses of tricyclic antidepressants in children and adolescents. Journal of the American Academy of Child \& Adolescent Psychiatry, 35(11), 1491-1501.

Zeiner, P. (1995). Body growth and cardiovascular function after extended (1.75 years) with methylphenidate in boys with attention-deficit hyperactivity disorder. Journal of Child \& Adolescent Psychopharmacology, 5(2), 129-138.

Zito, J.M., Safer, D.J., dosReis, S., Gardner, J.F., Boles, M., \& Lynch, F. (2000). Trends in the prescribing of psychotropic medications to preschoolers. Journal of the American Medical Association, 283(8), 1025-1030.

Zito, J.M., Safer, D.J., dosReis, S., Magder, L.S., Gardner, J.F., \& Zarin, D.A. (1999). Psychotherapeutic medication patterns for youth with attention deficit hyperactivity disorder. Archives of Pediatric \& Adolescent Medicine, 153(12), 1257-1263.

\section{PERMISSIONS AND COPYRIGHT}

All rights are reserved. No part of this publication may be reproduced, photocopied, faxed, stored in a retrieval system, or transmitted in any form or by any means, electronic, mechanical, recording or otherwise, without the prior written permission of the publisher.
Back issues are available for sale. Reproduction requires permission and payment of fees. It is illegal and a violation of federal copyright law to reproduce this publication without permission. Direct all inquiries to the permissions editor. 